\title{
THERAPEUTIC POTENTIAL OF VENOM PEPTIDES
}

\section{Richard J. Lewis ${ }^{\ngtr \ddagger}$ and Maria L. Garcia ${ }^{\S}$}

Venomous animals have evolved a vast array of peptide toxins for prey capture and defence. These peptides are directed against a wide variety of pharmacological targets, making them an invaluable source of ligands for studying the properties of these targets in different experimental paradigms. A number of these peptides have been used in vivo for proof-of-concept studies, with several having undergone preclinical or clinical development for the treatment of pain, diabetes, multiple sclerosis and cardiovascular diseases. Here we survey the pharmacology of venom peptides and assess their therapeutic prospects.

DINOFLAGELLATES Unicellular algae that produce a range of toxins that enter the food chain during blooms.

ENVENOMATION APPARATUS Highly specialized glands secreting peptides injected via hollow teeth, stings, harpoons and nematocyst tubules.
${ }^{*}$ Institute for Molecular Bioscience, The University of Queensland, St. Lucia 4072, Australia.

${ }^{\ddagger}$ Xenome Ltd, 50 Meiers Rd, Indooroopilly 4068,

Australia.

${ }^{s}$ Department of Ion Channels, Merck Research

Laboratories, PO Box 2000, Rahway, New Jersey 07065 , USA.

Correspondence to R.J.L. e-mail:

r.lewis@imb.uq.edu.au

doi:10.1038/nrd1197
Toxins have evolved in plants, animals and microbes multiple times as part of defensive and/or prey capture strategies. Non-peptide toxins are typically orally active and include many food-borne toxins of DINOFLAGELLATE origin, such as the ciguatoxins and brevetoxins which activate voltage-sensitive sodium channels ${ }^{1}$, the diarrhoetic shellfish poisons which inhibit protein phosphatases $^{2,3}$, and the paralytic shellfish poisons (saxitoxins) which inhibit sodium channels. Puffer fish and crabs apparently accumulate lethal levels of another sodiumchannel inhibitor (tetrodotoxin) from bacteria ${ }^{4}$, whereas certain frogs can accumulate alkaloids, such as batrachotoxin and epibatidine, through their diet ${ }^{5}$. Many of these toxins have proven to be invaluable research tools and have provided leads for potential new therapies. An example is provided by epibatidine and its analogues, which produce potent antinociception ${ }^{6,7}$, probably by activating certain nicotinic acetylcholine receptors that stimulate the release of noradrenaline in the spinal cord ${ }^{8}$.

By contrast, peptide toxins are usually found in animal venom associated with specialized ENVENOMATION APPARATUS that allows their delivery into the soft tissue of animals via subcutaneous, intramuscular or intravenous routes (FIG. 1). Most venoms comprise a highly complex mixture of peptides, often with diverse and selective pharmacologies. Despite this diversity, venom peptides seem to have evolved from a relatively small number of structural frameworks that are particularly well suited to addressing the crucial issues of potency and stability (FIG. 2). It is this evolved biodiversity that makes venom peptides a unique source of leads and structural templates from which new therapeutic agents might be developed.

In this review, peptides found in the venom of cone snails, spiders, scorpions, snakes, the Gila monster lizard and sea anemone (FIG. 1) are discussed in relation to their therapeutic potential, and that of the targets they modulate. Where possible, we focus on venom peptides that have been investigated for in vivo efficacy. The reader is directed to other publications that discuss related venom peptides that have been investigated in vitro in terms of their potency, selectivity and mechanism of action.

\section{Unravelling venom biodiversity}

As indicated above, crude venoms contain a diverse array of different peptides, many of which are bioactive. Nowhere is this diversity more apparent than within the small peptides (conotoxins and conopeptides) present in the venom of cone snails, a family of widely distributed marine molluscs (FIG. 3). These peptides are highly structured mini-proteins that have evolved in $\sim 500$ species of fish-, mollusc- and worm-hunting cone snails for rapid prey immobilization and defence (see FIG. 3 for examples). Their small size, relative ease of synthesis, structural stability and target specificity make them important pharmacological probes. It is estimated that $>50,000$ conopeptides exist, but $<0.1 \%$ have been 

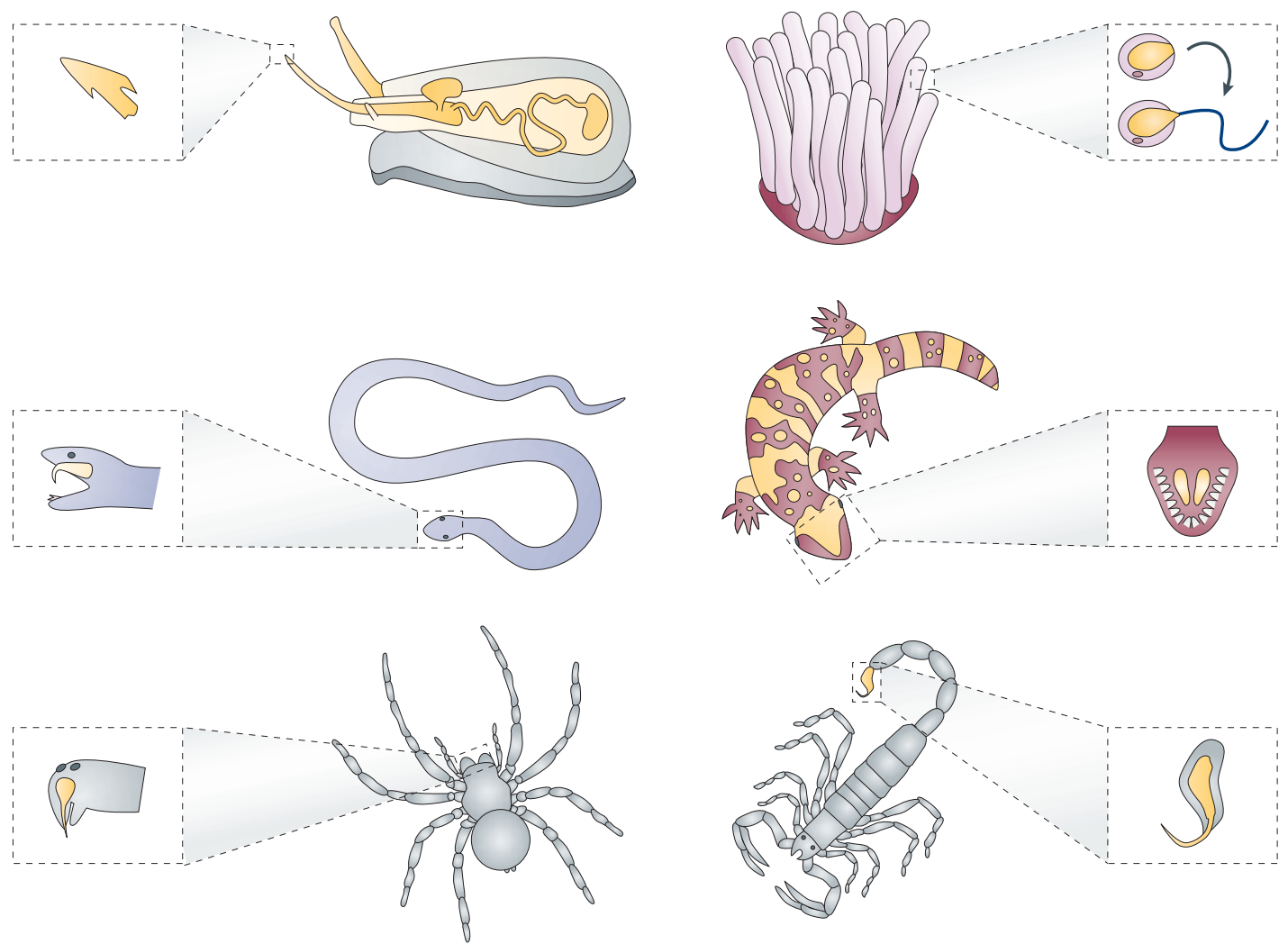

Figure 1 | Cone snail, sea anemone, snake, Gila monster, spider and scorpion produce venom peptides with therapeutic potential. All groups are widely distributed in tropical to temperate regions, except the Gila monster which is found from southwestern United States to central America. The envenomation apparatus are highlighted (harpoon, nematocysys, teeth and sting).

characterized pharmacologically. Of those characterized to date, a surprising number have been found to be highly selective for a diverse range of mammalian ion channels and receptors associated with pain signalling pathways, including the nicotinic acetylcholine receptors $(\alpha$-conotoxins $)$, the noradrenaline transporter $(\chi$-conopeptides), sodium channels $(\mu$ - and $\mu \mathrm{O}$-conotoxins), calcium channels ( $\omega$-conotoxins), the $N$-methylD-aspartate (NMDA) receptor (conantokins) and the neurotensin receptor (contulakins) (TABLE 1). Cone snails are not the only species that produce peptides in their venom; however, those found in spiders, snakes, sea anemones and scorpions are typically of larger size.

How are peptides of interest identified amongst the large numbers of related molecules that are present in animal venoms? In general, three approaches are taken. Traditionally, assay-directed fractionation has been used. The development of novel high-throughput assays for a diversity of targets, along with improved separation and sequencing capabilities, have simplified peptide isolation and characterization. For example, $\omega$-conotoxin GVIA ( $\omega$-GVIA) was first isolated from Conus geographus venom fractions that caused shaking in mice following intracerebroventricular administration ${ }^{9}$, whereas $\omega$-CVIA-D were isolated from fractions that inhibited binding of ${ }^{125}$ I-GVIA to rat brain membranes ${ }^{10}$. The polymerase chain reaction and chemical approaches (for example, mass spectrometry) are increasingly being used to overcome the bias associated with assay-directed methods, which identify the major activity (potency $x$ quantity) at the expense of less abundant components. Chemical synthesis of the peptide allows confirmation of activity and further characterization across multiple targets, both in vitro and in vivo.

\section{Optimizing venom peptides}

Venom peptides need to be sufficiently stable to survive chemical degradation in solution at ambient temperature and enzymatic degradation by processing proteases present in the venom itself ${ }^{11}$, as well as those in the tissues of prey species. This stability is often achieved naturally through the use of post-translational modifications (PTMs) and/or disulphide bonds which fold the peptide into a stabilized structure. Typical PTMs include amidation (C-terminal), sulphation (Tyr), bromination ( $\operatorname{Trp}$ ), glycosylation (Thr), $\gamma$-carboxylation (Glu), hydroxylation (Pro), pyroglutamation, N-C-cyclization and isomerization to $\mathrm{D}$-amino acids. Specific enzymes are used during the production of venom peptides to introduce these modifications at specific locations, which can enhance peptide bioavailability and potency in addition to stability. Despite these modifications, venom peptides are not always optimal for all requirements associated with potential therapeutic applications. Issues surrounding the therapeutic use of peptides include formulation, cost of production, stability, selectivity and mechanism 
of action. Chemical synthesis of analogues allows structure-activity relationships (SARs) to be developed that can guide the coordinated optimization of these features. As part of this process, optimized oxidation conditions need to be established to favour the correct formation of disulphide bonds after synthesis (see TABLE 1).

Identified complementary interactions between the peptide and its target can be used to define the docking of the peptide with the goal of guiding the design of analogues (including small molecules) with tailored properties at specific molecular targets (BOX 1). This approach is particularly relevant to the larger venom peptides, which are unlikely to escape the surveillance of the immune system. One limitation of peptides is their inability to cross epithelial layers, including the blood-brain barrier. Owing to their relatively large size and hydrophilic nature, the oral bioavailability of venom peptides ( 10-40 amino acids) is generally poor. This typically means that peptides need to be administered to the site of action by either intravenous, intrathecal, intraperitoneal, intramuscular, subcutaneous or epidural injection. Emerging approaches to improving peptide a $\omega$-CVID

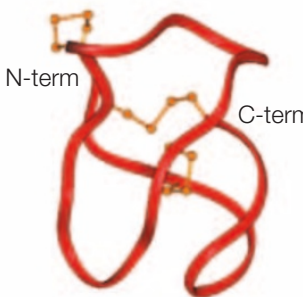

c $\mu$-PIIIA

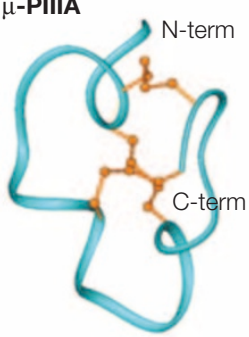

e $\chi$-MrlB

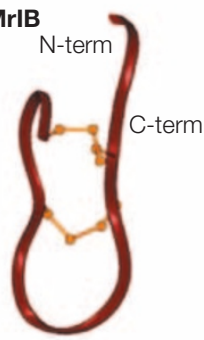

g Chlorotoxin

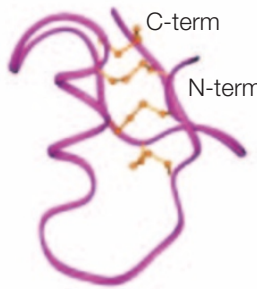

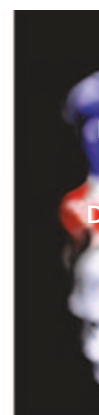
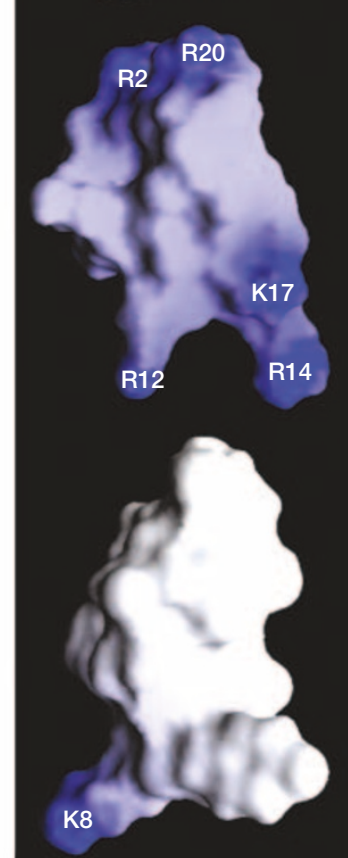

K8

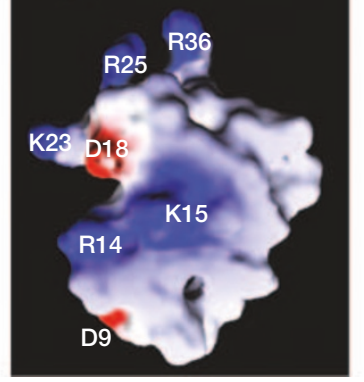

b $\alpha$-GID

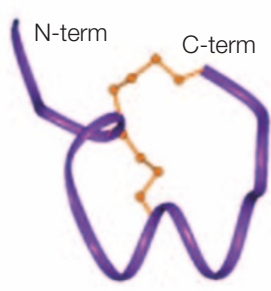

d ShK

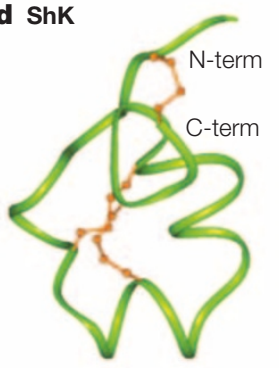

f GsMTx4

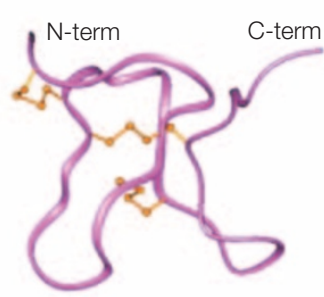

h MgTX

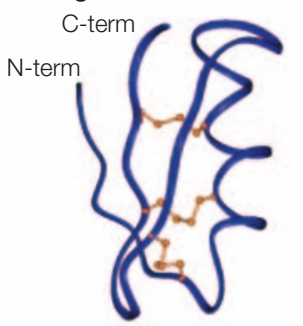

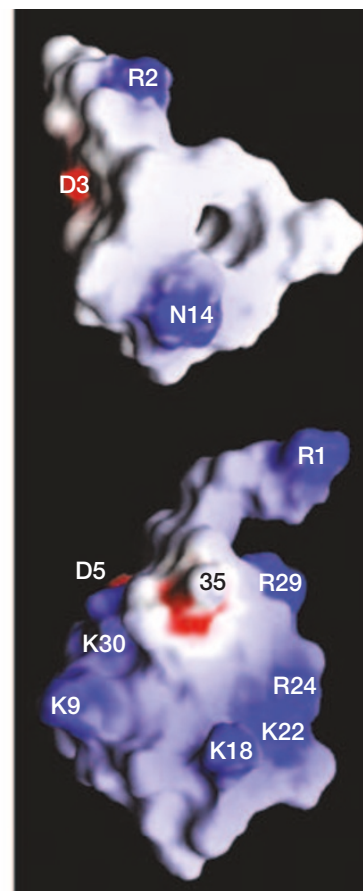
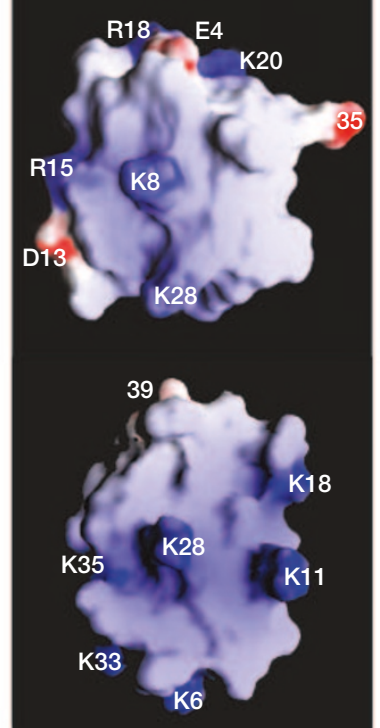

Figure 2 | Molecular structures of toxins with therapeutic potential. a $\mid \omega-C V I D^{10}$. b $\mid \alpha-G I D(1 M T Q)^{121}$. c $\mid \mu-P I I I A^{50}$. d $\mid$ ShK $(1 \mathrm{ROO})^{122} \cdot \mathbf{e}\left|\chi-\mathrm{MrlB}(1 \mathrm{EOO})^{96} . \mathbf{f}\right|$ GsMTx4 (1LQR) ${ }^{99} . \mathbf{g} \mid$ Chlorotoxin $(1 \mathrm{CHL})^{123} \cdot \mathbf{h} \mid$ Margatoxin $(1 \mathrm{MTX})^{124}$. For each structure a ribbon representation showing overall fold and disulphide connectivity (left), and an electrostatic surface (right) are shown (red areas negative, blue positive, grey hydrophobic). Note the structural similarities, but different electrostatic surfaces, displayed by a chloride-channel toxin (g) and a $\mathrm{K}^{+}$channel toxin (h). By contrast, the structures of the two $\mathrm{K}^{+}$channel toxins illustrated (d and $\mathbf{h}$ ) show considerable structural divergence. 
delivery, such as lipophilic modifications ${ }^{12}$, might eventually allow oral delivery to peripheral and central targets. However, combining targeted delivery with a restricted target distribution can be an advantage when a particular target of interest is found both centrally and peripherally, and efficacy is derived from drug interaction at the central sites, but side effects arise from an action of the drug in the periphery, for example.
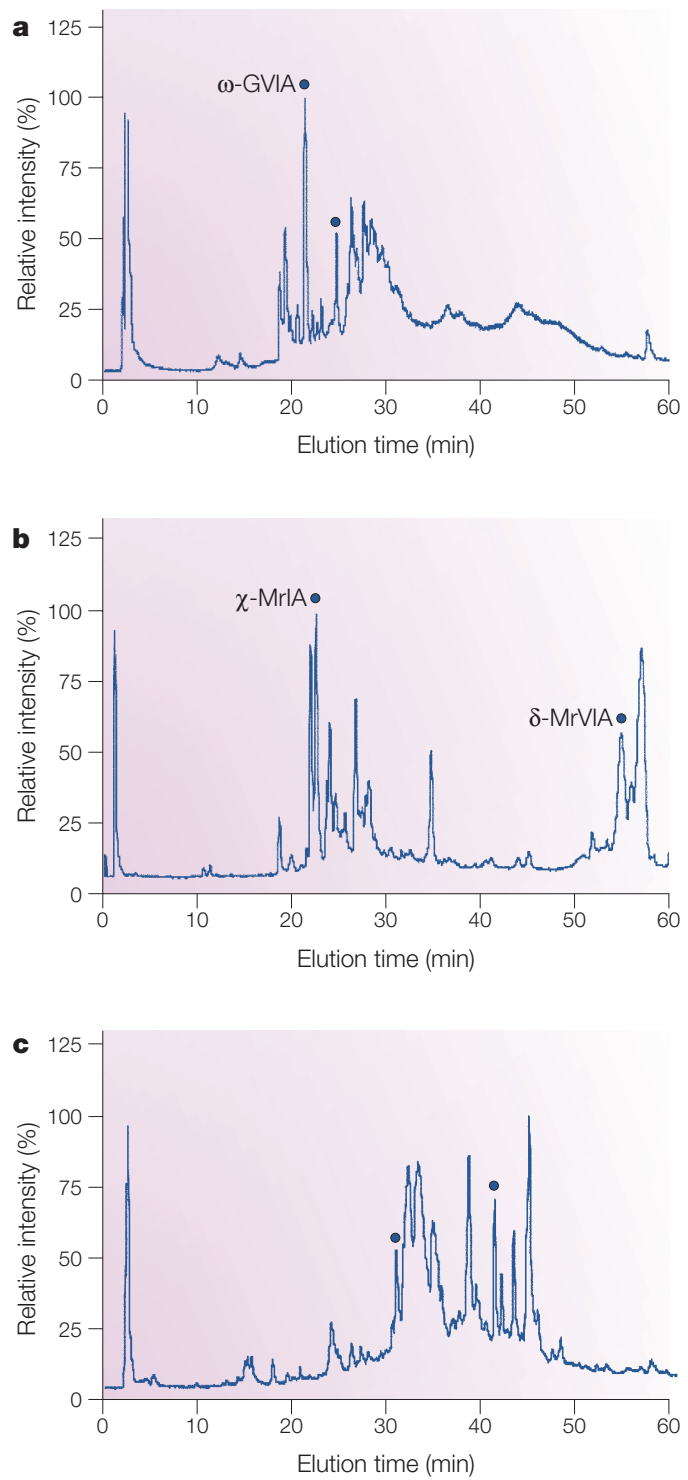

The selectivity and mechanism of action of venom peptides also needs to be taken into consideration in anticipation of putative adverse side effects. Most ionchannel modulators that are used in the clinic and that have good therapeutic indices are state-dependent block$\mathrm{ers}^{13}$. These compounds preferentially associate with a gating conformation of the channel that is relevant for drug efficacy; they derive safety from their lower affinity
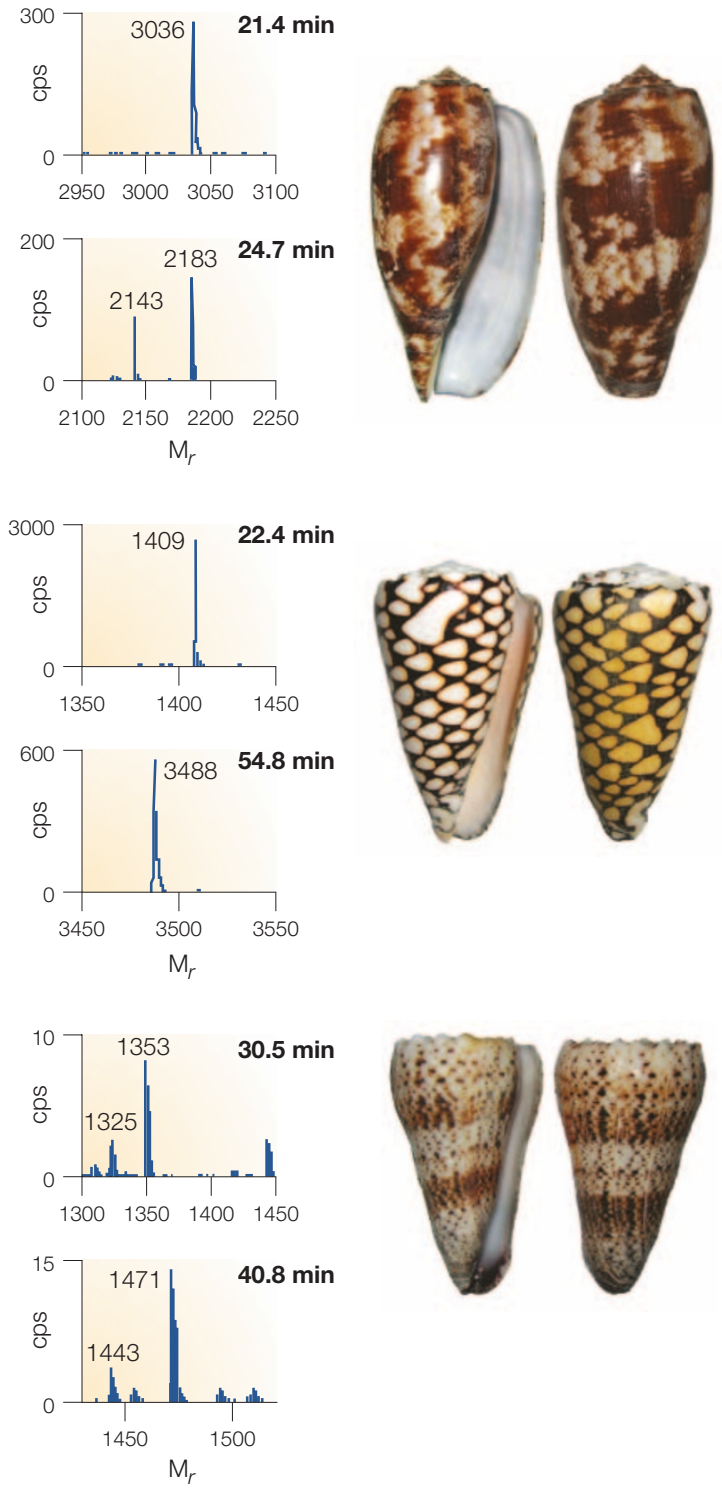

Figure 3 | Complexity of crude venom revealed by liquid chromatography/mass spectrometry (LC/MS) analyses of fish-, mollusc- and worm-hunting cone snails. a | Conus geographus. b | Conus marmoreus. c| Conus imperialis. The insets show mass spectra of known (labelled in the corresponding LC/MS) and uncharacterized venom peptides. A shell of each species is also shown indicating the typically wide aperture for fish-hunting cones (a), intermediate aperture for mollusc-hunting cones (b), and the narrow aperture for worm-hunting cones (c). LC/MS analysis was performed on a Zorbax SB-300A (150 × $2.1 \mathrm{~mm}, 5 \mu \mathrm{m}$ particle size) C3 column eluted with a linear gradient from $0.1 \%$ formic acid (aq) to $90 \%$ acetonitrile in $0.1 \%$ formic acid (aq) at a flow rate of $300 \mu \mathrm{l}$ per min (Agilent 1100)). Electrospray mass spectra were acquired on a SCIEX QSTAR Pulsar QqTOF mass spectrometer equipped with an atmospheric-pressure ionization source. Samples were analysed in the positive ion mode at a sprayer potential of $5 \mathrm{kV}$ over $\mathrm{m} / \mathrm{z}$ 650-2600. Note that several known conotoxins ( $\omega$-GVIA, $\chi$-MrIA and $\delta$-MrVIA) were present in large quantities, whereas other known conotoxins, including, for example, $\alpha$-Gl, $\mu$-GIIIA, $\alpha$-Iml and $\alpha$-ImIl, were present at trace levels or were undetectable in these batches of pooled venom. Spectra of three other marked peaks contained multiple uncharacterized conotoxins, typical of most peaks on each LC/MS trace. It is estimated that the venom of each species contains $>100$ unique peptides. Note also the different polarity profiles (the more hydrophobic peptides elute later) of the venom peptides of each species that further illustrates the chemical diversity in these venoms. cps, counts per second. 
for different conformational states of the channel that are present in other tissues, or which are found only in the absence of disease. So, small molecules can often achieve functional selectivity despite lacking target selectivity. In the case of pore-blocking peptides, the mechanisms of functional selectivity are not obvious, as it is thought that these agents bind with similar affinity to the different gating conformations of the channel. To overcome this limitation, it might be possible to exploit the relatively undeveloped families of gating-modifying peptides. Potassium-channel-gating modifiers, for example, seem to bind to a region of the protein that is only available when the channel opens ${ }^{14-16}$, and could display target selectivity because there is little conservation in the sequence of the putative receptor site for these peptides within related channels ${ }^{17}$. However, channel-gating modifiers have not been investigated for therapeutic benefit in animal models. One of the limitations in their use could be related to the difficulty of obtaining large amounts of these peptides. Improvements in their synthesis and folding will facilitate the evaluation of these agents ${ }^{18}$.

\section{Pharmacology of venom peptides}

Venom peptides target a wide variety of membranebound protein channels and receptors. Examples of the structural diversity of membrane protein targets with therapeutic potential are shown in FIG. 4 (see BOX 1 for further details). Venom peptides acting at these and other targets are described below.

Calcium channel peptides. It has long been established that $\mathrm{Ca}^{2+}$ influx into nerve terminals through voltagesensitive calcium channels (VSCCs) is the trigger that initiates neurotransmitter release. In recent years, much has been learned about the nature of VSCCs. These channels have been classified into six groups according to their electrophysiological and pharmacological properties, and are termed L-, N-, P-, Q-, T- and R-type channels ${ }^{19-21}$. Studies investigating the role of VSCCs in neurotransmitter release have indicated that the release of a particular neurotransmitter is coupled to the activity of different calcium channel subtypes in different neurons. In addition, multiple splice variants of calcium channels exist in central and peripheral tissues ${ }^{22}$. Given this diversity, considerable opportunity exists to develop selective inhibitors of VSCCs.

The $\omega$-conotoxins are unique tools with which to identify and determine the physiological role of different neuronal VSCCs. A range of different VSCC peptides are produced by cone snails ${ }^{9,10,23}$, spiders ${ }^{24-27}$ and snakes $^{28}$. As N-type $\left(\mathrm{Ca}_{\mathrm{v}} 2.2\right)$ VSCCs participate in the ascending pain pathways (see FIG.5), and are upregulated in the spinal cord in chronic pain states ${ }^{29}$ along with the auxiliary $\alpha 2 \delta 1$ subunit $^{30}$, it is not surprising that $\omega$-conotoxins specific for N-type VSCCs are potent analgesics ${ }^{31,32}$. Extensive SAR studies have allowed the development of a pharmacophore model for $\omega$-conotoxins $s^{33}$ that might allow the rational development of specific N-type VSCC inhibitors. Recently, $\omega$-CVID was found to inhibit an otherwise resistant VSCC found in parasympathetic nerve terminals, despite being $\sim 10^{6}$-fold selective for $\mathrm{N}$-type over P/Qtype VSCCs ${ }^{34}$. The implications of inhibiting this 'R-type' calcium channel for pain conditions are unclear, but these neurons arise from cell bodies in the spinal cord that could be involved in spinal signal processing.

\begin{tabular}{|c|c|c|c|c|}
\hline Source & Name & Sequence & Connectivity* & Action of class \\
\hline Cone snail & $\begin{array}{l}\alpha-G \mid \\
\alpha-G I D\end{array}$ & $\begin{array}{l}\text { ECCNPACGRHYSC }^{\ddagger} \\
\text { IR } \gamma \mathbf{C C S N P A C R V N N O H V C}\end{array}$ & $1-3,2-4$ & $\begin{array}{l}\text { Muscle nAChR } \\
\text { antagonist } \\
\text { Neuronal nAChR } \\
\text { antagonist }\end{array}$ \\
\hline Cone snail & $\mu-P I I A$ & PRLCCGFOKSCRSRQCKOHRCC ${ }^{\ddagger}$ & $1-4,2-5,3-6$ & $\begin{array}{l}\text { TXX-sensitive VSSC } \\
\text { inhibitor }\end{array}$ \\
\hline Cone snail & $\begin{array}{l}\omega-\mathrm{MVIIA} \\
\omega-\mathrm{CVID}\end{array}$ & $\begin{array}{l}\text { CKGKGAKCSRLMYDCCTGSCRSGKC }{ }^{\ddagger} \\
\text { CKSKGAKCSKLMYDCCSGSCSGTVGRC }{ }^{\ddagger}\end{array}$ & $1-4,2-5,3-6$ & Ca 2.2 inhibitors \\
\hline Cone snail & $\chi$-MrlA & NGVCCGYKLCHOC & $1-4,2-3$ & NET inhibitor \\
\hline Cone snail & $\rho-\mathrm{TIA}$ & FNWRCCLIPACRRNHKKFC ${ }^{\ddagger}$ & $1-3,2-4$ & $\begin{array}{l}\alpha_{1} \text {-Adrenoceptor } \\
\text { inhibitor }\end{array}$ \\
\hline Cone snail & Conantokin G & GE $\gamma \gamma L Q \gamma N Q \gamma L I R \gamma K S N$ & None & $\begin{array}{l}\text { NMDA receptor } \\
\text { inhibitor }\end{array}$ \\
\hline Cone snail & Contulakin G & PSEEGGSNAT ${ }_{g}$ KKPYIIL & None & $\begin{array}{l}\text { neurotensin receptor } \\
\text { agonist }\end{array}$ \\
\hline Spider & GsMTx4 & $\begin{array}{l}\text { GCLEFWWKCNPNDDKCCRPKLKCSKLFK } \\
\text { LCNFSSG }\end{array}$ & $1-4,2-5,3-6$ & $\begin{array}{l}\text { Mechanosensitive } \\
\text { channel inhibitor }\end{array}$ \\
\hline Scorpion & Chlorotoxin & $\begin{array}{l}\text { MCMPCFTDHQMARKCDDCCGGKGRGK } \\
\text { CYGPQCLCR }\end{array}$ & $1-4,2-6,3-7,5-3$ & $\begin{array}{l}\text { Chloride } \\
\text { channel inhibitor }\end{array}$ \\
\hline Scorpion & Margatoxin & $\begin{array}{l}\text { TIINVKCTSPKQCLPPCKAQFGQSAGAKCM } \\
\text { NGKCKCYPH }\end{array}$ & $1-4,2-5,3-6$ & $\begin{array}{l}\mathrm{K}_{\mathrm{v}} 1.1,1.2,1.3 \\
\text { channel blocker }\end{array}$ \\
\hline $\begin{array}{l}\text { Sea } \\
\text { anemone }\end{array}$ & ShK & $\begin{array}{l}\text { RSCIDTIPKSRCTAFQCKHSMKYRLSFCR } \\
\text { KTCGTC }\end{array}$ & $1-4,2-5,3-6$ & $\begin{array}{l}\mathrm{K}_{\mathrm{v}} 1.1,1.3 \text { channel } \\
\text { blocker }\end{array}$ \\
\hline
\end{tabular}

${ }^{*}$ Connectivity indicates the position of the cysteines involved in each specific disulphide bonds (for example, first to third and second to fourth as in $\alpha$-GID). ${ }^{\ddagger}$ Amidated. $\gamma, \gamma$-carboxyglutamate; O, hydroxyproline; P, pyroglutamate; $T_{g}$, glycosylated threonine. 


\section{Box 1 | Docking of an $\alpha$-neurotoxin onto the nicotinic acetylcholine receptor}

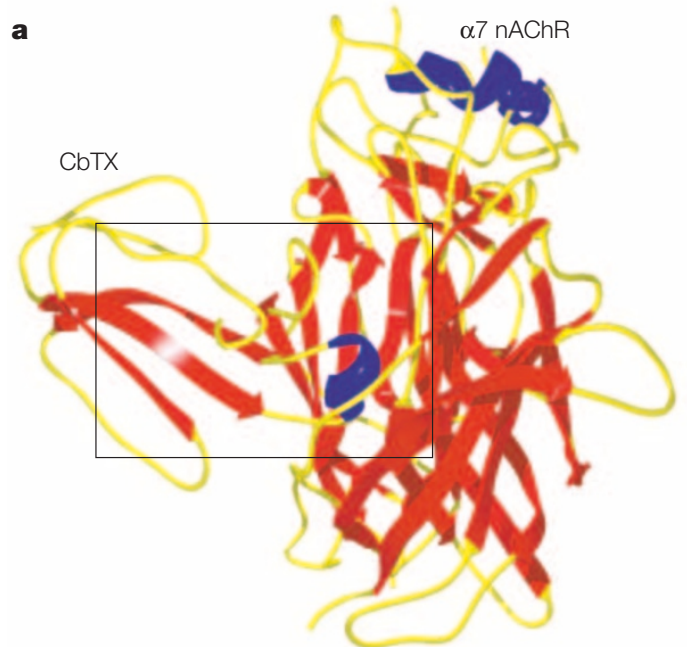

b

The figure shows an homology model of the $\alpha 7$ receptor constructed from acetylcholine (ACh)-binding protein ${ }^{129}$ with $\alpha$-cobratoxin docked into the aromatic cage that forms the ACh-binding pocket $^{130}(\mathbf{a})$. The expanded view (b) shows the Arg of cobratoxin interacting with aromatic residues that constitute the orthosteric site for ACh. With this knowledge, one can start to imagine how to design smaller inhibitors, or perhaps even agonists ${ }^{131}$, that act selectively at different nicotinic ACh receptors. On the basis of similar principles, it might be possible to design selective potassium-channel blockers based on our understanding of the modelled BgK-K 1.1 complex ${ }^{132}$. Homology models of G-protein-coupled receptors built from the X-ray structure of bovine rhodopsin ${ }^{133}$ also seem to have sufficient precision to guide the design of new modulators of these therapeutically important targets. Recent crystal structures of a voltage-dependent potassium channel $^{15}$, a chloride channel ${ }^{134}$, and the $\mathrm{N}$-methyl-D-aspartate receptor ligand-binding core ${ }^{135}$ might also prove suitable for similar pursuits. However, the lack of suitable crystal structures of membrane proteins closely related to the voltagesensitive sodium and calcium channels, natriuretic peptide receptor A and noradrenaline transporter presently limits their precision. Another approach to ligand design is to graft active-site residues into smaller scaffolds, such as those provided by toxins ${ }^{136}$.

Sub-nanomolar bolus intrathecal doses of $\omega$-MVIIA or $\omega$-CVID produce analgesia for up to 24 hours in inflammatory ${ }^{35}$ and neuropathic ${ }^{36}$ pain models (see FIG. 5), with $\omega$-CVID displaying a wider therapeutic index than $\omega$-MVIIA. $\omega$-MVIIA (SNX111/Ziconotide/Prialt; Elan) is in late Phase III trials, and $\omega$-CVID (AM336; AMRAD) is entering Phase II trials for the treatment of chronic pain. Inhibitors able to target specific VSCC splice variant/auxilliary subunit combinations specifically associated with ascending pain pathways could produce analgesia with fewer side effects.

Sodium-channel toxins. Like the structurally related VSCCs, voltage-sensitive sodium channels (VSSCs) are crucial to the functioning of the nervous system. On the basis of their susceptibility to blockade by tetrodotoxin (TTX), which acts at 'site 1' in the P-loop region of the $\alpha$-subunit, VSSCs can be divided into TTX-sensitive (TTX-S) and TTX-resistant (TTX-R) classes; members of both classes share considerable sequence similarity and are closely related structurally ${ }^{37}$. The former class includes the neuronal TTX-S type I/Na 1.1 channel, the type II/ $\mathrm{Na}_{\mathrm{v}} 1.2$ channel, the type III/Na $1.3, \mathrm{PN} 1 / \mathrm{Na}_{\mathrm{v}} 1.7$ and $\mathrm{PN} 4 / \mathrm{Na}_{\mathrm{v}} 1.6$ channels, and the skeletal muscle TTX-S $\mu 1 / \mathrm{Na}_{\mathrm{v}} 1.4$ channel. The TTX-R sodium channels include the cardiac $\mathrm{H} 1 / \mathrm{Na}_{\mathrm{v}} 1.5$ channel, which is partially TTX-resistant, and the neuronal TTX-R SNS/
PN3/ $\mathrm{Na}_{\mathrm{v}} 1.8$ and $\mathrm{NaN} / \mathrm{PN} 5 / \mathrm{Na}_{\mathrm{v}} 1.9$ channels (REF. 37). A number of these VSSC subtypes are implicated in clinical states such as pain (see FIG. 5), stroke and epilepsy. For example, there is now compelling evidence that $\mathrm{PN} 3 / \mathrm{SNS} / \mathrm{Na}_{\mathrm{v}} 1.8$, a TTX-R sodium channel located specifically in sensory neurons ${ }^{38,39}$, is important in neuropathic pain ${ }^{40,41}$. Given their crucial role in the central and peripheral nervous system, it is not surprising that a number of venoms from spiders ${ }^{42,43}$, sea anemone and coral $^{44-46}$, scorpions $s^{47}$, and cone snails ${ }^{48-50}$ have evolved to target these channels. In addition, an unusual spider toxin has been identified that inhibits proton-gated sodium channels associated with pain pathways ${ }^{51}$.

Although sodium-channel activators are typically toxic, subtype-selective inhibitors might have considerable therapeutic potential. Despite this therapeutic potential, little progress has been made towards the development of peptides that are subtype-selective inhibitors of VSSCs. Given the latent pharmacology revealed by TTX, pore blockers such as the $\mu$-conotoxin ${ }^{52}$ seem to hold most potential as subtype-selective inhibitors of VSSCs. By contrast, the intra-membrane local anaesthetic site, where many classes of small molecules act, is conserved across the different VSSCs and could be more problematic for conferring subtype discrimination. However, state- and frequencydependent blockade for many drugs that bind in this 
a $\mathrm{Ca}_{\mathrm{v}} 2.2$

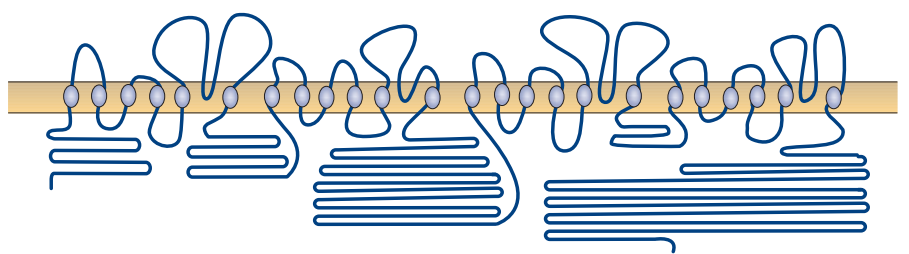

b $K_{v} 1.3$

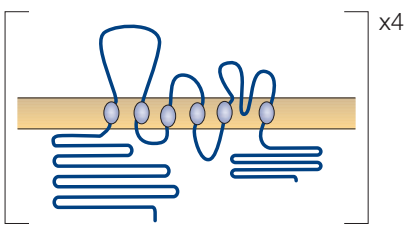

C $\mathrm{Na}_{\mathrm{v}} \mathbf{1 . 2}$

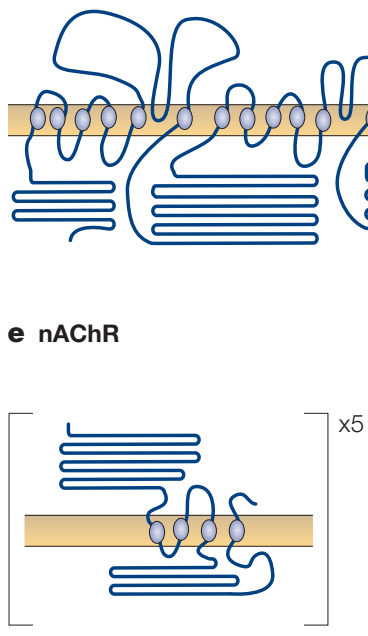

g NPRA

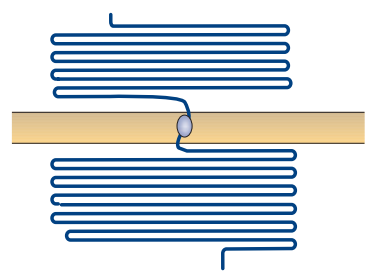

j NT-R-1

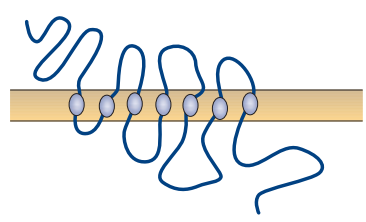

k ACE

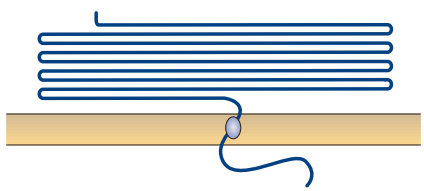

d $\mathrm{CIC}-3$

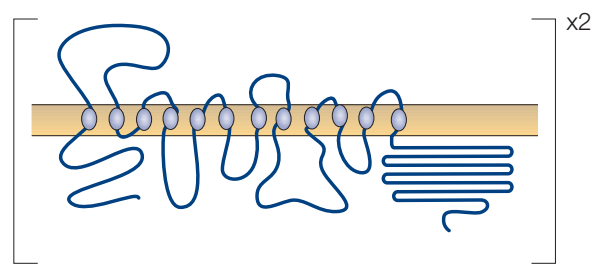

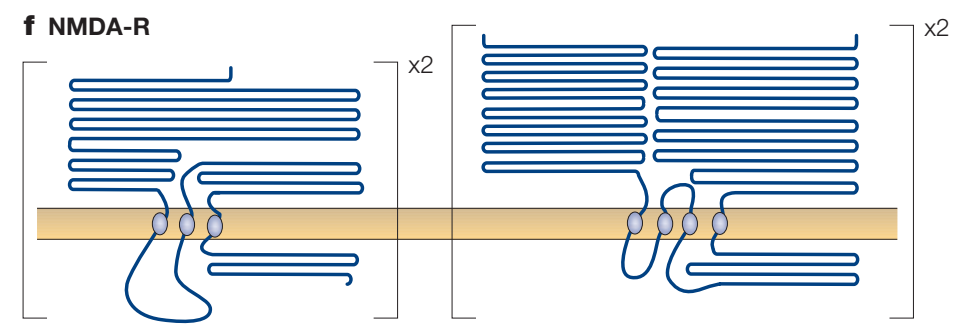

h GLP-1R

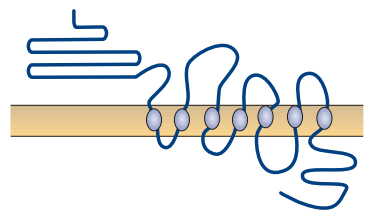

i $\alpha_{1 \mathrm{~B}}$-AR

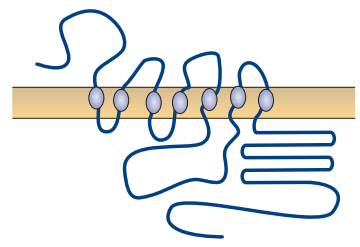

Figure 4 | Predicted topologies of membrane proteins targeted by venom peptides. a | Calcium channel Ca $2.2 \alpha$-subunit (human, NCBI-Protein accession Q00975) is inhibited by $\omega$-conotoxins that seem to act in or near the P-loops (partial membranespanning segments that create the selectivity filter), particularly those in domains $\|$ and IV of the channel ${ }^{125}$. b $\mid K^{+}$channel $K_{v} 1.3$ $\alpha$-subunit (human, accession NP_002223) forms a tetrameric assemblage. $\mathbf{c}$ | Sodium channel Na $1.2 \alpha$-subunit (human, accession Q99250). Site 1 toxins (TTX, STX and $\mu$-conotoxins) act at the P-loops (see $\mathbf{a})^{126}$. d | Chloride channel, CIC-3 (guinea-pig, accession Q9R279) is a functional dimer. e | Nicotinic ACh receptor $\alpha 7$ (human, accession P36544) is a pentamer. $\mathbf{f} \mid$ NMDA receptor (human, accession Q05586, Q13224] is probably a tetramer comprising, for example, dimers of two NR2B (right) and two NR1 (left) subunits. $\mathbf{g}$ | Natriuretic peptide receptor A (human, accession OYHUAR) which dimerizes on activation. $\mathbf{h}$ | Glucagon-like peptide 1 receptor (human, accession P43220) is a member of the GPCR superfamily. $\mathbf{i} \mid \alpha_{1 \mathrm{~B}}$-Adrenoceptor (hamster, accession $\mathrm{P} 18841$ ) is a member of GPCR superfamily (can form functional dimers). $\mathbf{j}$ | Neurotensin receptor NT1 (human, accession P30989) is a member of the GPCR superfamily. $\mathbf{k}$ | Angiotensin-converting enzyme (human, accession P22966) is a monomer. I | Noradrenaline transporter (human, accession P23975) can be a functional dimer. Representatives of several of these classes of membrane proteins have been crystalized, allowing predictive homology models of drug targets to be developed (see BOX 1). The shaded blue area in each panel represents the lipid bilayer of the cell. Membrane proteins are drawn to scale. ACE, angiotensin-converting enzyme; AR, adrenoceptor; GLP, glucagon-like peptide; GPCR, G-protein-coupled receptor; nAChR, nicotinic acetylcholine receptor; NET, noradrenaline transporter; NMDA, N-methyl-o-aspartate; NPRA, natriuretic peptide receptor A; NTR, neurotensin receptor; STX, saxitoxin; TTX, tetrodotoxin. 


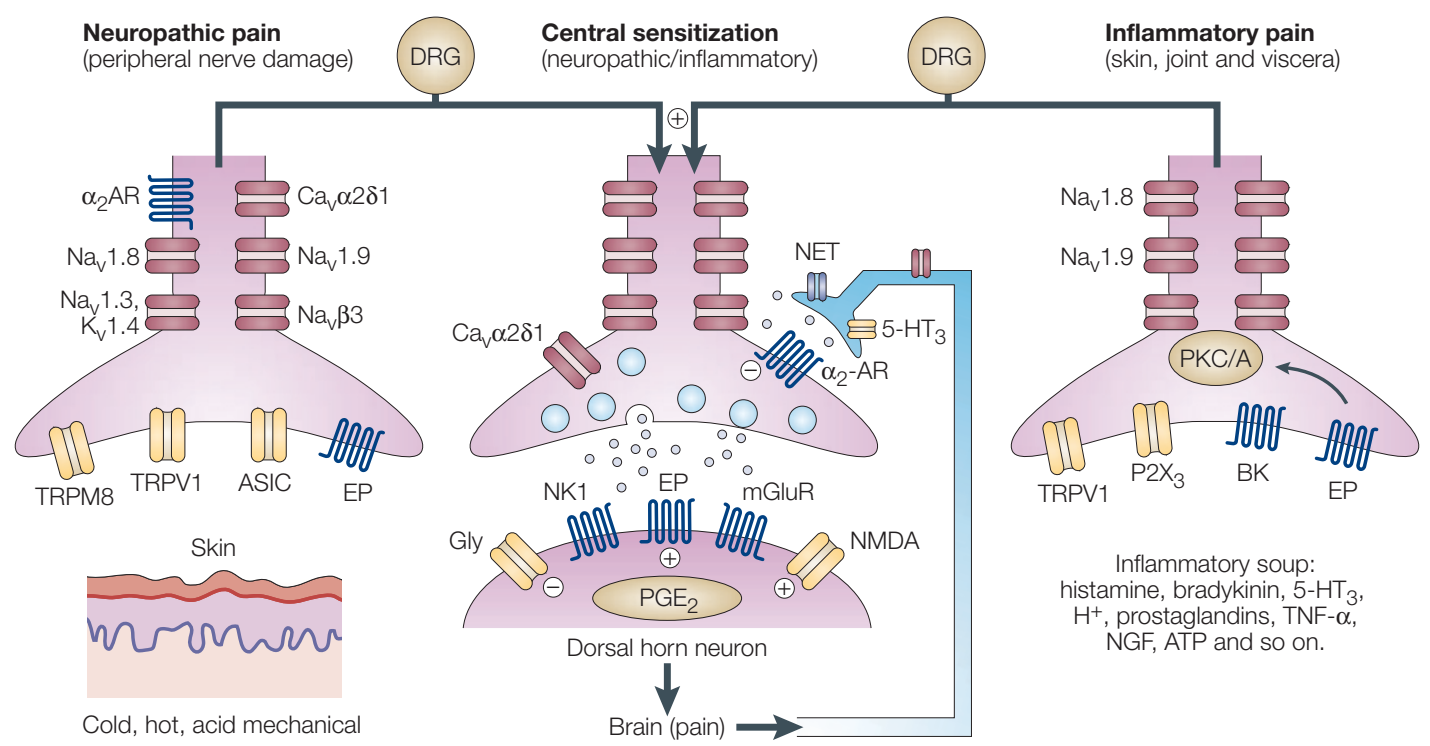

Figure 5 | Pain pathways. Illustrated are a number of selected targets known to be expressed by nociceptive primary afferent nerves (for example, Na 1.8, TRPV1, ASICs, EP and $\alpha_{2}$-adrenoceptors), presumed nociceptive dorsal horn neurons (for example, NK1 and NMDA receptor) and descending facilitatory and inhibitory modulatory pathways originating in the medulla ${ }^{127,128}$. Many of these targets are up- or downregulated in different pain states, and thus could be modulated by venom peptides to produce analgesia. Examples include the $\omega$-conotoxins ( $\mathrm{N}$-type calcium channel inhibitors) which inhibit ascending nociceptive pathways, and the $\chi$-conopeptides (noradernaline transporter inhibitors) which enhance descending inhibitory pathways. 5- $\mathrm{HT}_{3}$, 5-hydroxytryptamine; AR, adrenoceptor; ASIC, acid-sensitive ion channel; BK, bradykinin 1 and 2 receptors; DRG, dorsal root ganglia; EP, prostaglandin receptor 1; Gly, glycine receptor; mGluR, metabotrophic glutamate receptor; NET, noradrenaline transporter; NGF, nerve growth factor; NK1, neurokinin 1; NMDA, N-methyl-o-aspartate; $\mathrm{P} 2 \mathrm{X} 3$, purinoceptor $2 \mathrm{X} 3$; $\mathrm{PGE}_{2}$, prostaglandin $\mathrm{E}_{2} ; \mathrm{PKC} / \mathrm{A}$, protein kinase $\mathrm{C}$ and $\mathrm{A}$; TNF, tumour-necrosis factor; TRPM8, TRP channel member 8 (cold sensitive); TRPV1, transient receptor potential cation channel, member 1.

region, such as phenytoin, carbamazepine, lamotrigine and lidocaine, has allowed the therapeutic use of these compounds in the treatment of epilepsy, neuropathic pain and arrhythmias.

Potassium-channel toxins. Potassium channels are a large and diverse family of proteins that are implicated in the regulation of many cellular functions, such as smooth muscle and neuronal excitability, proliferation, electrolyte secretion and volume regulation. Peptide inhibitors have helped elucidate the physiological role of some potassium channels in native tissues, including $\mathrm{K}_{\mathrm{v}} 1$ channels in the enteric nervous system ${ }^{53}$, and highconductance calcium-activated potassium channels in smooth muscle tissues such as bladder ${ }^{54}$. Obviously, blocking potassium channels will lead to many pathophysiological conditions. There are, however, examples in which the blockade of a specific potassium channel can produce a desired therapeutic outcome. For instance, first-line therapy for the treatment of type 2 diabetes are sulphonylureas, a group of compounds that block the ATP-dependent potassium channel in pancreatic $\beta$-cells ${ }^{55}$. In addition, dofetilide (Tikosyn; Pfizer), an inhibitor of the cardiac rapid delayed rectifier channel $\mathrm{IK}_{r}$, has been approved by the US FDA for the conversion and maintenance of sinus rhythm in patients with atrial fibrillation ${ }^{56}$. Cognitive enhancers, such as linopirdine and XE-991, are blockers of cloned KCNQ channels that underlie the native muscarinic current in a variety of neurons ${ }^{57}$. These agents have been shown to enhance the stimulus-evoked release of neurotransmitters, including acetylcholine, in the central nervous system, and to improve learning and memory in behavioural animal models. In a number of clinical trials with chronic spinal cord injury and multiple sclerosis patients, the nonselective potassium-channel blocker 4-aminopyridine has been shown to produce improvements in sensory and motor function ${ }^{56}$. It is thought that in demyelinated axons, the expression and distribution of channels such as $\mathrm{K}_{\mathrm{v}} 1.1$ and $\mathrm{K}_{\mathrm{v}} 1.2$ is altered, leading to increased channel activity and, as a consequence, to axonal dysfunction. The erythrocyte calcium-activated potassium channel is the pathway responsible for potassium efflux from the cell that drives chloride and water loss. As such, blockers of the erythrocyte channel have utility in the treatment of sickle-cell anaemia by preventing erythrocyte dehydration ${ }^{58}$. Blockers of the voltage-gated potassium channel $\mathrm{K}_{\mathrm{v}} 1.3$ have been shown to inhibit the delayed-type hypersensitivity reaction to tuberculin in YUCATAN MINI-PIGS, indicating that these channels could be targets of immunosuppressants ${ }^{59,60}$. Together, these findings indicate that the inhibition of potassium channels can have important therapeutic consequences. Peptide blockers of potassium channels that bind to external epitopes represent an interesting alternative for drug intervention ${ }^{61}$. These peptides have been shown to display good selectivity and potency for certain potassium channels and, because of their lack of cell penetration, should not cause the side effects that result from binding to intracellular targets.
Yucatan mini-pigs are used experimentally because their immune system resembles the human situation. 
Of the numerous potassium-channel-blocking peptides that have been identified, only a small number have shown promising results in animals. The first peptide to be tested in vivo was margatoxin (MgTX) from the scorpion Centruroides margaritatus, which is a potent blocker of the voltage-gated potassium channels $\mathrm{K}_{\mathrm{v}} 1.1, \mathrm{~K}_{\mathrm{v}} 1.2$, and $\mathrm{K}_{\mathrm{v}} 1.3$ (REF. 70). In human $\mathrm{T}$ cells, $\mathrm{K}_{\mathrm{v}} 1.3$ channels control the resting membrane potential, and their blockade causes membrane depolarization ${ }^{62}$ and, as a consequence, an attenuation of the increase in cytoplasmic calcium levels that occur on T-cell activation ${ }^{59}$. In in vitro assays, $\mathrm{K}_{\mathrm{v}} 1.3$ blockers inhibit human $\mathrm{T}$-cell proliferation, indicating that $\mathrm{K}_{\mathrm{v}} 1.3$ channels represent a target for the development of novel immunosuppressants ${ }^{59,63,64}$. MgTX depolarizes the T cells of both pigs and humans in vitro ${ }^{59}$, with a plasma $\mathrm{t}_{1 / 2}$ of $\sim 2$ hours in pigs. MgTX also inhibits the delayed-type hypersensitivity reaction to tuberculin in the mini-pigs, as determined by both the size of induration and the extent of T-cell infiltration ${ }^{59}$. The effect of MgTX was similar in magnitude to that of the immunosuppressant agent FK506, although lower concentrations of peptide were needed to achieve similar efficacy. No major toxicity events were noticed in these experiments, with hypersalivation and diarrhoea ${ }^{53}$ observed during continuous infusion of the peptide. However, bolus intravenous injection of higher doses of MgTX led to plasma concentrations $>10 \mathrm{nM}$ that caused transient hyperactivity in the pigs, indicating a possible effect on $\mathrm{K}_{\mathrm{v}} 1.1$ and $\mathrm{K}_{\mathrm{v}} 1.2$ channels in the brain. A possible central effect has particular relevance to immunosuppressed patients who might have a compromised blood-brain barrier.

ShK from the sea anemone Stichodactyla helianthus also blocks $\mathrm{K}_{\mathrm{v}} 1.1$ and $\mathrm{K}_{\mathrm{v}} 1.3$ channels and has shown efficacy in animal models of multiple sclerosis. ShK has a different three-dimensional structure to MgTX and related scorpion toxins (see FIG. 2 $^{65}$, but blocks potassium channels by binding to the outer vestibule and plugging the pore, in a similar manner to MgTX. Multiple sclerosis is a disease of the central nervous system of immunological aetiology, and is characterized by disseminated patches of demyelination in the brain and spinal cord, which results in multiple and varied neurological symptoms and signs, usually with remissions and exacerbation. Recently, $\mathrm{K}_{\mathrm{v}} 1.3$ channels have been proposed to be crucial in the pathogenesis of multiple sclerosis and other autoimmune diseases ${ }^{66,67}$. Myelinreactive encephalitogenic rat T cells express high levels of $\mathrm{K}_{\mathrm{y}} 1.3$ channels after repeated antigenic stimulation in vitro ${ }^{67}$. Adoptive transfer of these $\mathrm{T}$ cells into rats induces experimental autoimmune encephalomyelitis, which can be reversed by ShK. In humans, activated myelin-reactive $\mathrm{T}\left(\mathrm{T}_{\mathrm{EM}}\right)$ cells from patients with multiple sclerosis express significantly higher levels of $\mathrm{K}_{\mathrm{v}} 1.3$ channels than naive or central memory $\mathrm{T}$ cells, and $\mathrm{K}_{\mathrm{v}} 1.3$ inhibitors such as ShK suppress proliferation of $\mathrm{T}_{\mathrm{EM}}$ cells $^{68}$. Therefore, selective $\mathrm{K}_{\mathrm{v}} 1.3$ inhibitors might represent an appropriate therapy for the treatment of autoimmune diseases such as multiple sclerosis, as well as perhaps type 1 diabetes, psoriasis and rheumatoid arthritis. The pharmacokinetic properties of ShK in different species are not known, and ways to deliver therapeutic concentrations of the peptide need to be considered. ShK is expected to produce similar side effects to MgTX, including effects on the enteric nervous system ${ }^{53}$. The potential central effects of ShK also need to be considered, because the blood-brain barrier could be compromised in autoimmune diseases.

Selective potassium-channel blockers might also have potential in the treatment of cancer, as human ether-a-go-go-related gene $(h E R G) \mathrm{K}^{+}$channels seem to be overexpressed in different tumours ${ }^{69,70}$. In this regard, the selectivity of ErgTx toxins ${ }^{71}$, BeKM-1 (REF. 72) and APETx-1 (REF. 73) for hERG $\mathrm{K}^{+}$channels might have therapeutic implications.

Chloride-channel toxins. Chloride channels are also among the many membrane proteins overexpressed in different types of cancers. Chlorotoxin isolated from the scorpion Leiurus quinquestriatus ${ }^{74}$ binds to specific $\mathrm{Ca}^{2+}$-activated chloride channels ${ }^{75}$ and certain tumours and gliomas, and therefore might have potential in the treatment of cancer ${ }^{76}$. Although recent studies indicate that chlorotoxin inhibits matrix metalloproteinase 2, which is also upregulated in gliomas ${ }^{77}$, and might not be a general chloride-channel inhibitor ${ }^{78}$, the radioactive ${ }^{131}$ I-chlorotoxin analogue has cytolytic activity, and therefore the potential to selectively affect tumours and gliomas of neuroectodermal origin ${ }^{79,80}$. On the basis of these findings, TransMolecular Inc. is running trials with ${ }^{131}$ I-TM-601 ( ${ }^{131}$ I-chlorotoxin) as an investigational new drug for the treatment of gliomas.

Toxins inhibiting nicotinic acetylcholine receptors. The $\alpha$-conotoxins are a rapidly growing class of small peptides that competitively inhibit nicotinic acetylcholine receptors (nAChRs). Similarly to the snake $\alpha$-neurotoxins which have been intensively studied ${ }^{81}, \alpha$-conotoxins bind at the interface between specific subunits, allowing them to discriminate among different $n A C h R$ subtypes $^{82}$. Muscle-selective $\alpha$-conotoxins (for example, $\alpha$-GI, see TABLE 1) or miniproteins engineered from $\alpha$-neurotoxins (BOX 1) could represent an alternative to the use of smallmolecule curare-mimetic muscle relaxants, which are used during surgery but have slower than ideal recovery periods $s^{83}$. As mentioned in the introduction, agonists of nAChRs function as analgesics. However, a novel $\alpha$-conotoxin, $\mathrm{Vc1}$.1, has been recently identified as having potential analgesic properties ${ }^{84}$.

Venom peptides for cardiovascular disease. The first example of a successful venom-based drug is captopril (Capoten; Anakena), which inhibits angiotensinconverting enzyme (ACE), an essential enzyme for the production of angiotensin, which is in turn a vasoconstrictor associated with hypertension. The route by which Cushman and Ondetti developed captopril at Bristol-Myers Squibb is described in BOX 2. ACE inhibitors continue to be an important class of antihypertensive agents, despite the development of alternative pharmacologies ${ }^{85}$, such as B-type natriuretic peptides ${ }^{86}$, which are approved for use in acutely decompensated 


\section{Box 2 | The development of captopril}

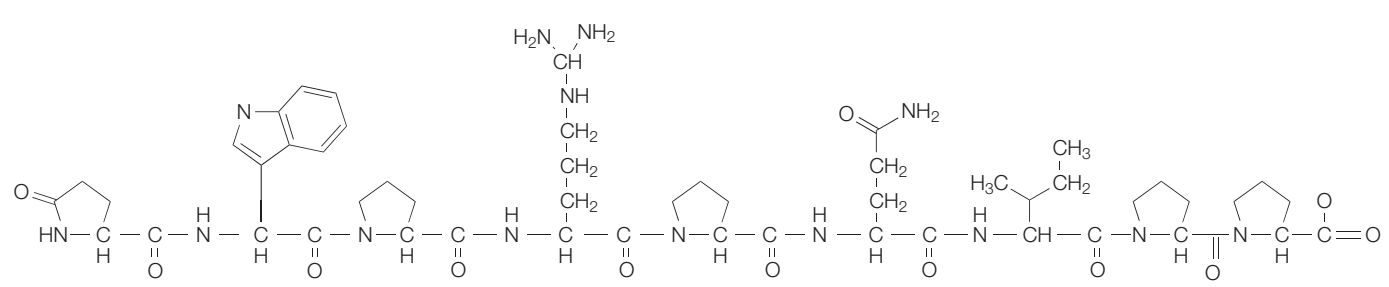

a Venom peptide (Teprotide)

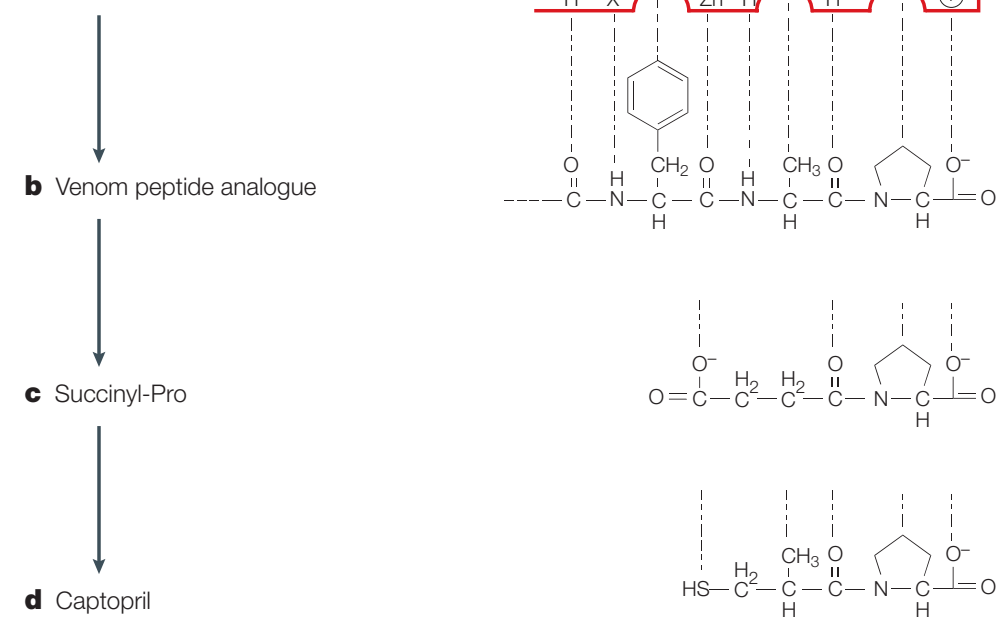

a I Teprotide was isolated from Bothrops jararaca venom and chosen as a lead because of its long-lasting in vivo activity, even though it was not orally active $e^{137,138}$. b I Structure-activity relationship (SAR) studies of teprotide indicated that a Phe-Ala-Pro sequence was a minimal pharmacophore to fit a hypothetical substrate-binding site on angiotensin-converting enzyme (ACE) (shown in red) developed from the crystal structure of carboxypeptidase $\mathrm{A}^{139}$. c I Succinyl-Pro was the first 'designed' ACE inhibitor, but showed low affinity despite ACE selectivity ${ }^{139}$. d I Further SAR studies around succinyl-Pro, including the addition of a sulphydryl group to improve interactions at the $\mathrm{Zn}^{2+}$ pocket, led to the orally available captopril, a true peptidomimetic one-fifth the size of teprotide ${ }^{139}$. In captopril, almost all of the functional groups contribute to overall activity, filling each of the substrate-binding sites to produce a high-affinity interaction with the active site on $\mathrm{ACE}^{140}$. The recent crystal structure of the ACE-lisinopril complex marks a new era in the development of better ACE inhibitors by revealing little structural similarity to carboxypeptidase $\mathrm{A}^{141}$.

chronic heart failure. A stabilized synthetic form of the natriuretic peptide from the green mamba Dendroapsis augusticeps also seems to have therapeutic potential ${ }^{87}$

Snake-venom peptides have since been used to guide the development of novel antithrombotics that act as competitive antagonists of the binding of ligand (for example, fibrinogen) to integrin $\alpha \operatorname{IIb} \beta 3$ on activated platelets. Among the most specific $\alpha \operatorname{IIb} \beta 3$ inhibitors is eptifibatide (Integrilin; Millennium Pharmaceuticals), a cyclic heptapeptide developed to mimic the high selectivity of barbourin ${ }^{88}$, a snake disintegrin that possesses a KDG motif, rather than the RGD motif found in other disintegrins ${ }^{89}$ and integrins ${ }^{90}$. Eptifibatide and the small-molecule RGDmimetic tirofiban (Aggrastat; Merck) ${ }^{91}$ are both used clinically in intravenous formulations. Orally active $\alpha I I b \beta 3$ antagonists with limited bioavailability have since been developed, but seem to be no more effective than widely used antiplatelet agents such as aspirin ${ }^{92}$. Ancrod from the venom of the Malayan pit viper
Agkistrodon rhodostoma, and batroxobin from the venom of Bothrops atrox moojeni, enzymatically cleave blood fibrinogen ${ }^{93}$ and seem to reduce neurological deficits when used in the early stages of stroke ${ }^{94}$.

Snake venoms also contain peptides with antihaemorrhagic properties. These include textilinin, a novel antifibrinolytic serine protease inhibitor from common brown snake (Pseudonaja textilis) venom ${ }^{95}$ that is now in preclinical development as a novel antibleeding product for use in open-heart surgery (Q70033; QRxPharma). Many of the wide range of haemostatic factors found in snake venoms have been used in the development of laboratory diagnostics (for example, those produced by Pentapharm Ltd and Gradipore) to measure levels of fibrinogen, prothrombin, blood-clotting factors and protein $\mathrm{C}$ associated with haemostatic disorders.

Venom peptides might also prove useful in the development of novel treatments for hypertension ( $\rho$-conopeptides) and atrial fibrillation (GsMTx-4). 
The $\rho$-conopeptides are selective, non-competitive inhibitors of the $\alpha_{1}$-adrenoceptor ${ }^{96,97}$. GsMTx-4 from the tarantula Grammostola spatulata ${ }^{98}$ is a novel blocker of mechanosensitive ion channels ${ }^{99}$ that inhibits atrial fibrillation ${ }^{100}$.

Noradrenaline transporter inhibitors. The noradrenaline transporter (NET) is important in reducing the concentration of neuronally released noradrenaline, and as a consequence influences learning and memory, as well as endocrine and autonomic functions ${ }^{101}$. Drugs that inhibit the NET have antidepressant and/or psychostimulant effects ${ }^{102}$, produce antinociception through the enhancement of descending inhibitory pathways in the spinal cord ${ }^{103}$, and might also be useful in the treatment of cardiovascular disorders and urinary incontinence ${ }^{104}$. The $\chi$-conopeptides are highly specific, non-competitive inhibitors of noradrenaline uptake by human and rat NET ${ }^{96}$. The pharmacology of the $\chi$-conopeptides was first identified in rat vas deferens contractility studies, which are sensitive to inhibition by $\mathrm{NET}^{96}$. Intrathecal $\chi$-MrIA produces analgesia in a hot-plate assay ${ }^{105}$, and is more potent and efficacious than morphine in a rat chronic constriction injury model of neuropathic pain ${ }^{106}$. A variant of $\chi$-MrIA (Xen2174), is being developed as a novel analgesic by Xenome Ltd. Interestingly, the binding site for $\chi$-conopeptides on the NET partially overlaps the tricyclic antidepressant binding site $\mathrm{s}^{107,108}$.

NMDA receptor antagonists. Conantokins are specific inhibitors of the NMDA receptor. They are helical peptides ${ }^{109,110}$ that competitively inhibit glutamate activation, especially at NR2B receptors ${ }^{111}$. Analogues of conantokin-G discriminate among different NMDA receptor subtypes in human brain ${ }^{112}$, and the antiepileptic effects of the conantokins ${ }^{113}$ have been explored by Cognetix Inc. Reflecting the probable role of NMDA receptors in pain neuroplasticity, Malmberg et al. ${ }^{114}$ showed that intrathecal conantokin-G and -T also have analgesic activity in pain models of tissue damage (formalin test), nerve injury (partial sciatic nerve ligation) and inflammation (complete Freund's adjuvant) in mice at doses that were $\sim 20$-fold lower than those required to impair motor function. So, subtype-specific inhibitors of the NMDA receptor also have therapeutic potential in the management of pain. Further studies are required to determine whether subtype-specific inhibitors of NMDA receptors are devoid of central adverse effects, including effects on memory and learning.

Neurotensin receptor agonists. Cone snails produce a glycosylated neurotensin analogue named contulakin$\mathrm{G}^{115}$ that is a potent analgesic in a wide range of animal models of pain ${ }^{116}$. Interestingly, contulakin-G is 100 -fold less potent than neurotensin for neurotensin receptor 1 (NTSR1), but $\sim 100$-fold more potent as an analgesic, indicating an additional mechanism(s) of action besides the neurotensin receptor. On the basis of its potency and wide therapeutic window, contulakin-G (CGX1160 ) is in early stage clinical development by Cognetix for the treatment of pain.

Venom peptides useful in diabetes. Glucagon-like peptide-1 (GLP1) is an insulinotropic hormone secreted from endocrine cells of the small and large intestine in a nutrient-dependent manner. GLP-1 inhibits gastric emptying and food intake, and controls blood glucose levels. A GLP-related peptide, exendin-4 from the venom of the Gila monster Heloderma suspectum ${ }^{117}$, has been shown to be active in vivo ${ }^{118}$. On the basis of this activity, exendin-4 (Exenatide; Amylin Pharmaceuticals) is presently in Phase III clinical trials for the treatment of type 2 diabetes. Surprisingly, GLPrelated peptides, including exendin-4, share structural homology to $\alpha$-latrotoxin from the black widow spider $^{119}$ and might have potential in the treatment of Alzheimer's disease $\mathrm{e}^{120}$.

\section{Future prospects}

As a consequence of their high selectivity, venom peptides have proved particularly useful for in vitro and in vivo proof-of-concept studies. However, for therapeutic applications, a number of issues associated with safety, pharmacokinetics and delivery need to be addressed. Optimization of peptide delivery to peripheral and central targets will help to determine whether or not these peptides can be considered candidates for drug development. Peptides that block channels by altering the gating mechanism might have potential to become selective potassium-channel inhibitors, whereas poreblocking toxins could be designed to be selective inhibitors of subtypes of sodium channels. It remains to be determined how many of the peptides that are present in venoms can find a clinical utility.
1. Lewis, R. J., Molgo, J. \& Adams, D. J. in Seafood and Freshwater Toxins (ed. Botana, L.) 419-447 (Marcel Dekker, New York, 2000).

2. Honkanen, R. E. \& Golden, T. Regulators of serine/threonine protein phosphatases at the dawn of a clinical era? Curr. Med. Chem. 9, 2055-2075 (2002).

3. Dounay, A. B. \& Forsyth, C. J. Okadaic acid: the archetypal serine/threonine protein phosphatase inhibitor. Curr. Med. Chem. 9, 1939-1980 (2002).

4. Noguchi, T. et al. Vibrio alginolyticus, a tetrodotoxinproducing bacterium, in the intestines of the fish Fugu vermicularis vermicularis. Mar. Biol. 94, 625-630 (1987).

5. Daly, J. W. Ernest Guenther award in chemistry of natural products. Amphibian skin: a remarkable source of biologically active arthropod alkaloids. J. Med. Chem. $\mathbf{4 6}$, 445-452 (2003).
An important review describing the origin and chemistry of frog alkaloid by the pioneer of the field. 6. Badio, B. \& Daly, J. W. Epibatidine, a potent analgetic and nicotinic agonist. Mol. Pharmacol. 45, 563-569 (1994).

7. Bannon, A. W. et al. Broad-spectrum, non-opioid analgesic activity by selective modulation of neuronal nicotinic acetylcholine receptors. Science 279, 77-81 (1998).

8. Li, X. \& Eisenach, J. C. Nicotinic acetylcholine receptor regulation of spinal norepinephrine release. Anesthesiology 96. 1450-1456 (2002).

9. Olivera, B. M., McIntosh, J. M., Cruz, L. J., Luque, F. A. \& Gray, W. R. Purification and sequence of a presynaptic peptide toxin from Conus geographus venom. Biochemistry 23, 5087-5090 (1984).

Isolation and initial characterisation of the first $\omega$-conotoxin.
10. Lewis, R J et al. Novel $\omega$-conotoxins from Conus catus discriminate among neuronal calcium channel subtypes. J. Biol. Chem. 275, 35335-35344 (2000).

11. Milne, T. J., Abbenante, G., Tyndall, J. D., Halliday, J. \& Lewis, R. J. Isolation and characterization of a cone snail protease with homology to CRISP proteins of the pathogenesis-related protein superfamily. J. Biol. Chem. 278, 31105-31110 (2003).

A post-translational processing enzyme characterized from cone snails, that showed surprising homology to the pathogenesis-related proteins.

12. Blanchfield, J. T. et al. Synthesis, structure elucidation, in vitro biological activity, toxicity and Caco-2 cell permeability of lipophilic analogues of $\alpha$-conotoxin MII. J. Med. Chem. 46, 1266-1272 (2003). 
13. Yellen, G. The voltage-gated potassium channels and their relatives. Nature $\mathbf{4 1 9}, 35-42$ (2002).

14. Jiang, Y., Ruta, V., Chen, J., Lee, A. \& MacKinnon, R. The principle of gating charge movement in a voltage-dependent $\mathrm{K}^{+}$channel. Nature 423, 42-48 (2003).

15. Jiang, Y. et al. X-ray structure of a voltage-dependent $\mathrm{K}$ channel. Nature 423, 33-41(2003).

\section{First X-ray structure of a voltage sensitive potassium} channel revealing novel insights into gating charge movement.

16. Ruta, V., Jiang, Y., Lee, A., Chen, J. \& MacKinnon, R. Functional analysis of an archaebacterial voltage-dependent $\mathrm{K}^{+}$channel. Nature 422, 180-185 (2003).

17. Li-Smerin, Y. \& Swartz, K. J. Helical structure of the $\mathrm{COOH}$ terminus of S3 and its contribution to the gating modifies toxin receptor in voltage-gated ion channels. J. Gen. Physiol. 117, 205-217 (2001).

18. Takahashi, H. et al. Solution structure of hanatoxin1, a gating modifier of voltage-dependent $\mathrm{K}^{+}$channels: common surface features of gating modifier toxins. J. Mol. Biol. 297 $771-780(2000)$

19. Dunlap, K., Luebke, J. \& Turner, T. Exocytotic $\mathrm{Ca}^{2+}$ channels in mammalian central neurons. Trends Neurosci. 18, 89-98 (1995)

20. Randall, A. D. The molecular basis of voltage-gated $\mathrm{Ca}^{2+}$ channel diversity: time for T? J. Memb. Biol. 161, 207-213 (1998)

21. Randall, A. D. \& Tsien, R. W. Pharmacological dissection of multiple types of $\mathrm{Ca}^{2+}$ channel currents in rat cerebellar granule neurons. J. Neurosci. 15, 2995-3012 (1995).

22. Lin, Z., Haus, S., Edgerton, J. \& Lipscombe, D. Identification of functionally distinct isoforms of the $\mathrm{N}$-type $\mathrm{Ca}^{2+}$ channel in rat sympathetic ganglia and brain. Neuron 18, 153-166 (1997).

23. Olivera, B. M. et al. Neuronal calcium channel antagonists. Discrimination between calcium channel subtypes using $\omega$-conotoxin from Conus magus venom. Biochemistry 26, 2086-2090 (1987)

24. Mintz, I. M., Venema, V. J., Adams, M. E. \& Bean, B. P. Inhibition of $\mathrm{N}$ - and L-type $\mathrm{Ca}^{2+}$ channels by the spider venom toxin $\omega$-Aga-IIIA. Proc. Natl Acad. Sci. USA 88 6628-6631 (1991)

25. Mintz, I. M. et al. P-type calcium channels blocked by the spider toxin $\omega$-Aga-IVA. Nature 355, 827-829 (1992).

26. Newcomb, R. et al. Selective peptide antagonist of the class E calcium channel from the venom of the tarantula Hysterocrates gigas. Biochemistry 37, 15353-15362 (1998).

27. Wang, X. H. et al. Discovery and structure of a potent and highly specific blocker of insect calcium channels. J. Biol. Chem. 276, 40306-40312 (2001)

28. de Weille, J. R., Schweitz, H., Maes, P., Tartar, A. \& Lazdunski, M. Calciseptine, a peptide isolated from black mamba venom, is a specific blocker of the L-type calcium channel. Proc. Natl Acad. Sci. USA 88, 2437-2440 (1991).

29. Cizkova, D. et al. Localization of $\mathrm{N}$-type $\mathrm{Ca}^{2+}$ channels in the rat spinal cord following chronic constrictive nerve injury. Exp. Brain. Res. 147, 456-463 (2002).

30. Luo, Z. D. et al. Upregulation of dorsal root ganglion $\alpha 2 \delta$ calcium channel subunit and its correlation with allodynia in spinal nerve-injured rats. J. Neurosci. 21, 1868-1875 (2001).

31. Malmberg, A. B. \& Yaksh, T. L. Effect of continuous intrathecal infusion of $\omega$-conopeptides, $\mathrm{N}$-type calciumchannel blockers, on behaviour and antinociception in the formalin and hot-plate tests in rats. Pain 60, 83-90 (1995)

The first report that $\omega$-conotoxin produced potent antinociception effects that indicate a therapeutic potential for this class of toxins.

32. Wang, Y. X., Gao, D., Pettus, M., Phillips, C. \& Bowersox, S. S. Interactions of intrathecally administered Ziconotide, a selective blocker of neuronal N-type voltagesensitive calcium channels, with morphine on nociception in rats. Pain $\mathbf{8 4}, 271-281$ (2000).

33. Nielsen, K., Schroeder, T. \& Lewis, R. J. Structure-activity relationships of $\omega$-conotoxins. J. Mol. Recognit. 13, 55-70 (2000)

34. Adams, D. J., Smith, A. B., Schroeder, C. I., Yasuda T \& Lewis R. J. $\omega$-Conotoxin CVID inhibits a pharmacologically distinct voltage-sensitive calcium channel associated with transmitter release from preganglionic nerve terminals. J. Biol. Chem. 278, 4057-4062 (2003).

35. Smith, M., Cabot, P. J., Ross, F. B., Robertson, A. D. \& Lewis, R. J. The novel N-type calcium channel blocker, AM336, produces potent dose-dependent antinociception after intrathecal dosing in rats and inhibits substance $\mathrm{P}$ release in rat spinal cord slices. Pain $\mathbf{9 6}$ 119-127 (2002).

36. Scott, D. A., Wright, C. E.\& Angus, J. A. Actions of intrathecal $\omega$-conotoxins CVID, GVIA, MVIIA, and morphine in acute and neuropathic pain in the rat. Eur. J. Pharmacol. 451, 279-286 (2002)
37. Goldin, A. L. et al. Nomenclature of voltage-gated sodium channels. Neuron 28, 365-368 (2000).

38. Akopian, A. N., Sivilotti, L. \& Wood, J. N. A tetrodotoxinresistant voltage-gated sodium channel expressed by sensory neurons. Nature 379, 257-262 (1996). Discovery of the first neuronal TTX-resistant sodium channel.

39. Rabert, D. K. et al. A tetrodotoxin-resistant voltage-gated sodium channel from human dorsal root ganglia, hPN3/SCN10A. Pain 78, 107-114 (1998).

40. Porreca, F. et al. A comparison of the potential role of the tetrodotoxin-insensitive sodium channels, PN3/SNS and NaN/SNS2, in rat models of chronic pain. Proc. Natl Acad. Sci. USA 96, 7640-7644 (1999).

41. Gold, M. S. et al. Redistribution of $\mathrm{Na} 1.8$ in uninjured axons enables neuropathic pain. J. Neurosci. 23, 158-166 (2003). Key contribution on how $\mathrm{Na}_{\mathrm{v}} 1.8$ contributes to neuropathic pain.

42. Nicholson, G. M., Willow, M., Howden, M. E. \& Narahashi, T. Modification of sodium channel gating and kinetics by versutoxin from the Australian funnel-web spider Hadronyche versuta. Pflugers Arch. 428, 400-409 (1994).

43. Omecinsky, D. O., Holub, K. E., Adams, M. E. \& Reily, M. D. Three-dimensional structure analysis of $\mu$-agatoxins: further evidence for common motifs among neurotoxins with diverse ion channel specificities. Biochemistry 35 2836-2844 (1996).

44. Vincent, J. P., Balerna, M., Barhanin, J., Fosset, M. \& Lazdunski, M. Binding of sea anemone toxin to receptor sites associated with gating system of sodium channel in synaptic nerve endings in vitro. Proc. Natl Acad. Sci. USA 77, 1646-1650 (1980)

45. Gonoi, T. et al. Mechanism of action of a polypeptide neurotoxin from the coral Goniopora on sodium channels in mouse neuroblastoma cells. Mol. Pharmacol. 29, 347-354 (1986).

46. Norton, R. S. Structure and structure-function relationships of sea anemone proteins that interact with the sodium channel. Toxicon 29, 1051-1084 (1991).

47. Possani, L. D., Becerril, B., Delepierre, M. \& Tytgat, J. Scorpion toxins specific for $\mathrm{Na}^{+}$-channels. Eur. J. Biochem. 264, 287-300 (1999).

48. Cruz, L. J. et al. Conus geographus toxins that discriminate between neuronal and muscle sodium channels. J. Biol. Chem. 260, 9280-9288 (1985).

49. Fainzilber, M., Kofman, O., Zlotkin, E. \& Gordon, D. A new neurotoxin receptor site on sodium channels is identified by a conotoxin that affects sodium channel inactivation in molluscs and acts as an antagonist in rat brain. J. Biol. Chem. 269, 2574-2580 (1994).

50. Shon, K. J. et al. $\mu$-Conotoxin PIIIA, a new peptide for discriminating among tetrodotoxin-sensitive Na channe subtypes. J. Neurosci. 18, 4473-4481 (1998).

51. Escoubas, P. et al. Isolation of a tarantula toxin specific for a class of proton-gated $\mathrm{Na}^{+}$channels. J. Biol. Chem. $\mathbf{2 7 5}$ 25116-25121 (2000).

52. Moczydlowski, E., Olivera, B. M., Gray, W. R. \& Strichartz, G. R. Discrimination of muscle and neurona Na-channel subtypes by binding competition between $\left[{ }^{3} \mathrm{H}\right]$ saxitoxin and $\mu$-conotoxins. Proc. Natl Acad. Sci. USA 83, 5321-5325 (1986)

53. Suarez-Kurtz, G., Vianna-Jorge, R., Pereira, B. F. Garcia, M. L. \& Kaczorowski, G. J. Peptidyl blockers of Shaker-type $\mathrm{K}_{v} 1$ channels elicit twitches in guinea-pig ileum by blocking $\mathrm{K}_{v} 1.1$ at the enteric nervous system and enhancing acetylcholine release. J. Pharmacol. Exp. Ther. 289, 1517-1522 (1999).

54. Suarez-Kurtz, G., Garcia, M. L. \& Kaczorowski, G. J. Effects of charybdotoxin and iberiotoxin on the spontaneous motility and tonus of different guinea-pig smooth muscle tissues J. Pharmacol. Exp. Ther. 259, 439-443 (1991).

55. Inagaki, $\mathrm{N}$ et al. Reconstitution of IK : an inward rectifier subunit plus the sulfonylurea receptor. Science $\mathbf{2 7 0}$, 1166-1170 (1995).

56. Wickenden, A. D. $\mathrm{K}^{+}$channels as therapeutic drug targets Pharmacol. Ther. 94, 157-182 (2002).

57. Coghlan, M. J., Carroll, W. A. \& Gopalakrishnan, M. Recent developments in the biology and medicinal chemistry of potassium channel modulators: update from a decade of progress. J. Med. Chem. 44, 1-27 (2001).

58. Brugnara, C. Therapeutic strategies for prevention of sickle cell dehydration. Blood Cells Mol. Dis. 27, 71-80 (2001).

59. Koo, G. C. et al. Blockade of the voltage-gated potassium channel K 1.3 inhibits immune responses in vivo. J. Immunol. 158, 5120-5128 (1997).

This study used toxins to determine the role played by $K_{v} 1.3$ in the immune response.

60. Koo, G. C. et al. Correolide and derivatives are novel immunosuppressants blocking the lymphocyte $\mathrm{K} 1.3$ potassium channels. Cell. Immunol. 197, 99-107 (1999).
61. Garcia, M. L., Gao, Y.-D., McManus, O. B. \& Kaczorowski, G. J. Potassium channels: from scorpion venoms to highresolution structure. Toxicon 39, 739-748 (2001).

62. Koschak, A. et al. Subunit composition of brain voltagegated potassium channels determined by Hongotoxin-1, a novel peptide derived from Centruroides limbatus venom. J. Biol. Chem. 273, 2639-2644 (1998).

63. Leonard, R. J., Garcia, M. L., Slaughter, R. S. \& Reuben, J. P. Selective blockers of voltage-gated $\mathrm{K}^{+}$channels depolarize human T lymphocytes: mechanism of the antiproliferative effect of charybdotoxin. Proc. Natl Acad. Sci. USA $\mathbf{8 9}$ 10094-10098 (1992).

64. Price, M., Lee, S. C. \& Deutsch, C. Charybdotoxin inhibits proliferation and IL2 production in human peripheral blood Iymphocytes. Proc. Natl Acad. Sci. USA 86, 10171-10175 (1989).

65. Kalman, K. et al. ShK-Dap ${ }^{22}$, a potent K,1.3-specific immunosuppressive polypeptide. J. Biol. Chem. 273, 32697-32707 (1998)

66. Beeton, C. et al. A novel fluorescent toxin to detect and investigate $\mathrm{K}_{1} 1.3$ channel up-regulation in chronically activated T lymphocytes. J. Biol. Chem. 278, 9928-9937 (2003).

67. Beeton, C. et al. Selective blockade of T lymphocyte $\mathrm{K}^{+}$ channels ameliorates experimental autoimmune encephalomyelitis, a model for multiple sclerosis. Proc. Nat Acad. Sci. USA 98, 13942-13947 (2001) Discovery that $K_{1} 1.3$ plays a key role in the development and maintainance of multiple sclerosis.

68. Wulff, H. et al. The voltage-gated $\mathrm{K}_{v} 1.3 \mathrm{~K}^{+}$channel in effector memory T cells as new target for MS. J. Clin. Invest. 111, 1703-1713 (2003).

69. Pardo, L. A. et al. Oncogenic potential of EAG K ${ }^{+}$channels. EMBO J. 18, 5540-5547 (1999).

70. Bianchi, L. et al. HERG encodes a $\mathrm{K}^{+}$current highly conserved in tumors of different histogenesis: a selective advantage for cancer cells? Cancer Res. 58, 815-822 (1998).

71. Lecchi, M. et al. Isolation of a long-lasting EAG-related gene-type $\mathrm{K}^{+}$current in $\mathrm{MMQ}$ lactotrophs and its accommodating role during slow firing and prolactin release. J. Neurosci. 22, 3414-3425 (2002).

72. Korolkova, Y. V. et al. New binding site on common molecular scaffold provides HERG channel specificity of scorpion toxin BeKm-1. J. Biol. Chem. 277, 43104-43109 (2002).

73. Diochot, S., Loret, E., Bruhn, T., Beress, L. \& Lazdunski, M. APETX1, a new toxin from the sea anemone Anthopleura elegantissima, blocks voltage-gated human ether-a-go-gorelated gene potassium channels. Mol. Pharmacol. 64 59-69 (2003).

74. DeBin, J. A., Maggio, J. E. \& Strichartz, G. R. Purification and characterization of chlorotoxin, a chloride channe ligand from the venom of the scorpion. Am. J. Physiol. 264 C361-C369 (1993)

75. Dalton, S. et al. Chlorotoxin-sensitive $\mathrm{Ca}^{2+-a c t i v a t e d ~ C-}$ channel in type $\mathrm{R} 2$ reactive astrocytes from adult rat brain. Glia 42, 325-339 (2003).

76. Ullrich, N., Gillespie, G. Y. \& Sontheimer, H. Human astrocytoma cells express a unique chloride current. Neuroreport. 7, 343-347 (1995)

77. Deshane, J., Garner, C. C. \& Sontheimer, H. Chlorotoxin inhibits glioma cell invasion via matrix metalloproteinase-2. J. Biol. Chem. 278, 4135-4244 (2003).

78. Maertens, C., Wei, L., Tytgat, J., Droogmans, G. \& Nilius, B. Chlorotoxin does not inhibit volume-regulated, calciumactivated and cyclic AMP-activated chloride channels. Br. J. Pharmacol. 129, 791-801 (2000).

79. Soroceanu, L., Gillespie, Y., Khazaeli, M. B. \& Sontheimer, H. Use of chlorotoxin for targeting of primary brain tumors. Cancer Res. 58, 4871-4879 (1998).

80. Lyons, S. A., O'Neal, J. \& Sontheimer, H. Chlorotoxin, a scorpion-derived peptide, specifically binds to gliomas and tumors of neuroectodermal origin. Glia 39, 162-173 (2002).

81. Antil-Delbeke, S. et al. Molecular determinants by which long chain toxins from snake venom interacts with the neuronal $\alpha$ 7-nicotinic acetylcholine receptor. J. Biol. Chem. 275, 29594-29601 (2001)

82. Mclntosh, J. M., Santos, A. D. \& Olivera, B. M. Conus peptides targeted to specific nicotinic acetylcholine recepto subtypes. Annu. Rev. Biochem. 68, 59-88 (1999).

83. Tuba, Z., Maho, S. \& Vizi, E. S. Synthesis and structureactivity relationships of neuromuscular blocking agents. Curr. Med. Chem. 9, 1507-1536 (2002).

84. Sandall, D. W. et al. A novel $\alpha$-conotoxin identified by gene sequencing is active in suppressing the vascular response to selective stimulation of sensory nerves in vivo. Biochemistry 42, 6904-6911 (2003).

85. Dei Cas, L., Metra, M., Nodari, S., Dei Cas, A. \& Gheorghiade, M. Prevention and management of chronic heart failure in patients at risk. Am. J. Cardiol. 91, 10F-17F (2003). 
86. Sudoh, T., Kangawa, K., Minamino, N. \& Matsuo, H. A new natriuretic peptide in porcine brain. Nature $\mathbf{3 3 2}, 78-81$ (1988).

87. Chen, H. H., Lainchbury, J. G. \& Burnett, J. C. Natriuretic peptide receptors and neutral endopeptidase in mediating the renal actions of a new therapeutic synthetic natriuretic peptides dendroapsis natriuetic peptide. J. Am. Coll. Cardiol. 40, 1186-1191 (2002)

88. Scarborough, R. M. et al. Design of potent and specific integrin antagonists. Peptide antagonists with high specificity for glycoprotein llb-Illa. J. Biol. Chem. 268 , 1066-1073 (1993).

89. Scarborough, R. M. et al. Characterization of the integrin specificities of disintegrins isolated from American pit viper venoms. J. Biol. Chem. 268, 1058-1065 (1993).

90. Pierschbacher, M. D. \& Ruoslahti, E. Cell attachment activity of fibronectin can be duplicated by small synthetic fragments of the molecule. Nature 309, 30-33 (1984). Discovery that cyclic RGD mimics bind to fibrinectin.

91. Hartman, G. D. et al. Non-peptide fibrinogen receptor antagonists. 1. Discovery and design of exosite inhibitors. J. Med. Chem. 35, 4640-4642 (1992). Design of the first non-peptidic inhibitor of fibrinogen developed from the RGD motif found in integrins.

92. Bennett, J. S. Novel platelet inhibitors. Annu. Rev. Med. $\mathbf{5 2}$ 161-184 (2001).

93. Bell, W. R. Jr. Defibrinogenating enzymes. Drugs $\mathbf{5 4}$, S18-S30 (1997)

94. Samsa, G. P., Matchar, D. B., Williams, G. R. \& Levy, D. E. Cost-effectiveness of ancrod treatment of acute ischaemic stroke: results from the Stroke Treatment with Ancrod Trial (STAT). J. Eval. Clin. Pract. 8, 61-70 (2002).

95. Filippovich, I. et al. A family of textilinin genes, two of which encode proteins with antihaemorrhagic properties. Br. J. Haematol. 119, 376-384 (2002).

96. Sharpe, I. A. et al. Two new classes of conopeptides inhibit the $\alpha_{1}$-adrenoceptor and noradrenaline transporter. Nature Neurosci. 4, 902-907 (2001).

Discovery of the first peptide inhibitors of the $\alpha_{1}$-adrenoceptor and noradrenaline transporter. Both classes were shown to act at allosteric sites on their targets.

97. Sharpe, I. A. et al. Allosteric $\alpha$-adrenoceptor antagonism by the conopeptide $\rho$-TIA. J. Biol. Chem. 2003 Jun 24; [epub ahead of print]

98. Suchyna, T. M. et al. GsMTx-4 from Grammostola spatulata. J. Gen. Physiol. 115, 583-598 (2000).

99. Oswald, R. E., Suchyna, T. M., Mcfeeters, R., Gottlieb, P. \& Sachs, F. Solution structure of peptide toxins that block mechanosensitive ion channels. J. Biol. Chem. 277, 34443-34450 (2002)

100. Bode, F., Sachs, F. \& Franz, M. R. Tarantula peptide inhibits atrial fibrillation. Nature 409, 35-36 (2001).

101. Ressler, K. J. \& Nemeroff, C. B. Role of norepinephrine in the pathophysiology and treatment of mood disorders. Biol. Psychiatry 46, 1219-1233 (1999).

102. Charney, D. S. Monoamine dysfunction and the pathophysiology and treatment of depression. J. Clin. Psychiatry 59, S11-S14 (1998).

103. Millan, M. J. Descending control of pain. Prog. Neurobiol. 66, 355-474 (2002)

104. Andersson, K. E. Advances in the pharmacological control of the bladder. Exp. Physiol. 84, 195-213 (1999).

105. Mclntosh, J. M. et al. Isolation and characterization of a novel Conus peptide with apparent antinociceptive activity. J. Biol. Chem. 275, 32391-32397 (2000).

106. Nielsen, C. K., Ross, F. B., Lewis, R. J., Drinkwater, R. \& Smith, M. T. Antiallodynic efficacy of the conopeptide, Mr1A in rats with neuropathic pain. Proc. 10th World Congress Pain A822-P92 (2002).

107. Bryan-Lluka, L. J., Bonisch, H. \& Lewis, R. J. $\chi$-Conopeptide MrlA partially overlaps the desipramine and cocaine binding sites on the human norepinephrine transporter. J. Biol. Chem. 2003 Jul 1; [epub ahead of print].

108. Sharpe, I. A. et al. Inhibition of the norepinephrine transporter by the venom peptide $\chi$-MrlA: Site of action, Na dependence, and structure-activity relationship. J. Biol. Chem. 2003 July 28; [epub ahead of print]
109. Skjærbæk, N., Nielsen, K. J., Lewis, R. J., Alewood, P. F. \& Craik, D. J. Determination of the structure of conantokin- $G$ and conantokin-T by CD and NMR spectroscopy. J. Biol. Chem. 272, 2291-2299 (1997).

110. Nielsen, K. J. et al. Structure activity studies of conantokins as human NMDA receptor modulators. J. Med. Chem. 42 415-426 (1999).

111. Donevan, S. D. \& McCabe, R. T. Conantokin G is an NR2B selective competitive antagonist of $\mathrm{N}$-methyl-D-aspartate receptors. Mol. Pharmacol. 58, 614-623 (2000).

112. Ragnarsson, L., Mortensen, M., Dodd, P. R. \& Lewis, R. J. Spermine modulation of the glutamate NMDA receptor is differentially responsive to conantokins in normal and Alzheimer's disease human cerebral cortex. J. Neurochem. 81, 765-779 (2002).

113. Jimenez, E. C. et al. Conantokin-L, a new NMDA receptor antagonist: determinants for anticonvulsant potency. Epilepsy Res. 51, 73-80 (2002).

114. Malmberg, A. B., Gilbert, H., McCabe, R. T. \& Basbaum, A. I. Powerful antinociceptive effects of the cone snail venomderived subtype-selective NMDA receptor antagonists conantokins G and T. Pain 101, 109-116 (2003).

115. Craig, A. G. et al. Contulakin-G, an O-glycosylated invertebrate neurotensin. J. Biol. Chem. 274, 13752-13579 (1999)

116. Wagstaff, J. D, Layer, R. T. and Craig, A. G. Venoms to Drugs Conf., Heron Island, Queensland, Australia, 14-19 July (2002).

117. Eng, J., Kleinman, W. A. Singh, L., Singh, G. \& Raufman, P. Isolation and characterization of exendin-4, an exendin-3 analogue, from Heloderma suspectum venom. Further evidence for an exendin receptor on dispersed acini from guinea pig pancreas. J. Biol. Chem. 267, 7402-7405 (1992)

118. Szayna, M. et al. Exendin-4 decelerates food intake, weight gain, and fat deposition in Zucker rats. Endocrinology 141 1936-1941 (2000).

119. Holz, G. G \& Habener, J. F. Black widow spider $\alpha$-latrotoxin: a presynaptic neurotoxin that shares structural homology with the glucagon-like peptide-1 family of insulin secretagogic hormones. Comp. Biochem. Physiol. B 121, 177-184 (1998)

120. Perry, T. \& Greig, N. H. The glucagon-like peptides: a new genre in therapeutic targets for intervention in Alzheimer's disease. J. Alzheimers Dis. 4, 487-496 (2002).

121. Nicke, A. et al. Isolation, structure, and activity of GID, a novel $\alpha 4 / 7$-conotoxin with an extended $\mathrm{N}$-terminal sequence. J. Biol. Chem. 278, 3137-3144 (2003).

122. Tudor, J. E., Pallaghy, P. K., Pennington, M. W. \& Norton, R. S. Solution structure of ShK toxin, a novel potassium channel inhibitor from a sea anemone. Nature Struct. Biol. $\mathbf{3}$, 317-320 (1996)

123. Lippens, G., Najib, J., Wodak, S. J. \& Tartar, A. NMR sequential assignments and solution structure of chlorotoxin, a small scorpion toxin that blocks chloride channels. Biochemistry 34, 13-21 (1995).

124. Johnson, B. A., Stevens, S. P. \& Williamson, J. M. Determination of the three-dimensional structure of margatoxin by ${ }^{1} \mathrm{H},{ }^{13} \mathrm{C},{ }^{15} \mathrm{~N}$ triple-resonance nuclea magnetic resonance spectroscopy. Biochemistry $\mathbf{3 3}$, 15061-15070 (1994).

125. Ellinor, P. T., Zhang, J. F., Horne, W. A. \& Tsien, R. W. Structural determinants of the blockade of $\mathrm{N}$-type calcium channels by a peptide neurotoxin. Nature $\mathbf{3 7 2}, 272-275$ (1994).

126. Dudley, S. C. Jr, Todt, H., Lipkind, G. \& Fozzard, H. A. A $\mu$-conotoxin-insensitive $\mathrm{Na}^{+}$channel mutant: possible localization of a binding site at the outer vestibule. Biophys. J. 69, 1657-1665 (1995).

127. Julius, D. \& Basbaum, A. I. Molecular mechanisms of nociception. Nature 413, 203-210 (2001).

128. Scholz, J. \& Woolf, C. J. Can we conquer pain? Nature Neurosci. Suppl. 5, 1062-1067 (2002).

129. Brejc, K. et al. Crystal structure of an ACh-binding protein reveals the ligand-binding domain of nicotinic receptors. Nature 411, 269-276 (2001).

The first high-resolution structure of the AChbinding protein, which has proved invaluable in developing predictive homology models of mammalian AChRs.
130. Fruchart-Gaillard, C et al. Experimentally based model of a complex between a snake toxin and the alpha 7 nicotinic receptor. Proc. Natl Acad. Sci. USA 99, 3216-3221 (2002).

131. Hogg, R. C., Hopping, G., Alewood, P. F., Adams, D. J. \& Bertrand, D. $\alpha$-Conotoxins PnIA and [A10L]PnIA stabilize different states of the $\alpha$ 7-L247T nicotinic acetylcholine receptor. J. Biol. Chem. 278, 26908-26914 (2003).

132. Gilquin, B. et al. Structure of the BgK-K 1.1 complex based on distance restraints identified by double mutant cycles. Molecular basis for convergent evolution of $\mathrm{K} 1$ channel blockers. J. Biol. Chem. 277, 37406-37413 (2002)

133. Palczewski, K. et al. Crystal structure of rhodopsin: A G protein-coupled receptor. Science 289, 739-745 (2000) The first mammalian GPCR crystal structure, which has greatly enhanced the quality of GPCR homology models.

134. Dutzler, R., Campbell, E. B., Cadene, M., Chait, B. T. \& MacKinnon, R. X-ray structure of a ClC chloride channel at 3.0 A reveals the molecular basis of anion selectivity. Nature 415, 287-294 (2002).

First crystal structure of an anion channel, revealing a surprising architecture among the membrane spanning segments.

135. Furukawa, H. \& Gouaux, E. Mechanisms of activation, inhibition and specificity: crystal structures of the NMDA receptor NR1 ligand-binding core. EMBO J. 22, 2873-2885 (2003)

136. Martin, L. et al. Rational design of a CD4 mimic that inhibits HIV-1 entry and exposes cryptic neutralization epitopes. Nature Biotechnol. 21, 71-76 (2003).

137. Ondetti, M. A. et al. Angiotensin-converting enzyme inhibitors from the venom of Bothrops jararaca. Isolation, elucidation of structure and synthesis. Biochemistry 19, 4033-4039 (1971).

Discovery of a biologically active peptide that led to the development of the drug Captopril.

138. Ondetti, M. A. Structural relationships of angiotensin converting-enzyme inhibitors to pharmacologic activity. Circulation 77, 174-178 (1988).

139. Cushman, D. W. \& Ondetti, M. A. Design of angiotensin converting enzyme inhibitors. Nature Med. 5, 1110-1113 (1999).

140. Cushman, D. W., Cheung, H. S., Sabo, F. F. \& Ondetti, M. A. Design of potent competitive inhibitors of angiotensinconverting enzyme. Carboxyalkanoyl and mercaptoalkanoyl amino acids. Biochemistry 16, 5484-5491 (1977)

141. Natesh, R., Schwager, S. L., Sturrock, E. D. \& Acharya, K. R. Crystal structure of the human angiotensin-converting enzyme-lisinopril complex. Nature 421, 551-554 (2003). A pivotal structure that could provide the insights needed to develop improved antihypertensives.

Acknowledments

We thank lain Sharpe, Christina Schroeder, Sebastien Dutertre and Alun Jones for help in preparing the figures. Supported by grants from the NHMRC and ARC, Australia.

\section{(4) Online links}

\section{DATABASES}

The following terms in this article are linked online to:

LocusLink: http://www.ncbi.nlm.nih.gov/LocusLink/

GLP1 | NTSR1

Online Mendelian Inheritance in Man:

http://www.ncbi.nlm.nih.gov/Omim/

Alzheimer's disease | multiple sclerosis | psoriasis |

type 1 diabetes | type 2 diabetes

\section{FURTHER INFORMATION}

Encyclopedia of Life Sciences: http://www.els.net

Cognetix: http://www.cognetix.com/

Cone shell conotoxins:

http://grimwade.biochem.unimelb.edu.au/cone/

University of Queensland Institute for Molecular Bioscience: http://www.imb.uq.edu.au/

Venom to Drugs Conference book:

http://www.venomstodrugs.com/Nenoms_Abstract book.pdf

Xenome: http://www.xenome.com/

Access to this interactive links box is free online. 